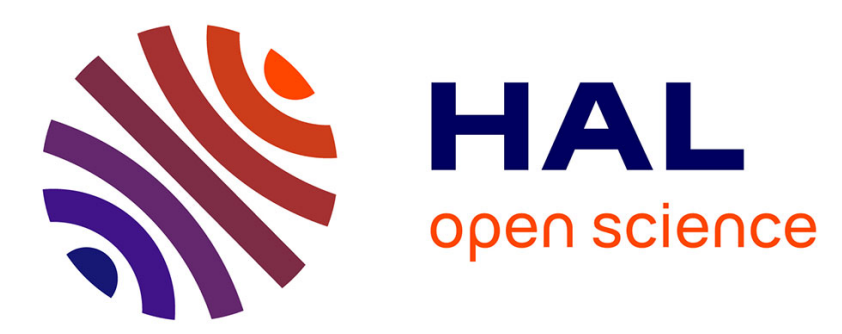

\title{
Bidirectional transfer of Engrailed homeoprotein across the plasma membrane requires PIP2
}

Irène Amblard, Edmond Dupont, Isabel D. Alves, Julie Miralvès, Isabelle Queguiner, Alain Joliot

\section{- To cite this version:}

Irène Amblard, Edmond Dupont, Isabel D. Alves, Julie Miralvès, Isabelle Queguiner, et al.. Bidirectional transfer of Engrailed homeoprotein across the plasma membrane requires PIP2. Journal of Cell Science, 2020, 10.1101/2020.01.21.913566 . hal-03082837

\section{HAL Id: hal-03082837 https://hal.science/hal-03082837}

Submitted on 21 Dec 2020

HAL is a multi-disciplinary open access archive for the deposit and dissemination of scientific research documents, whether they are published or not. The documents may come from teaching and research institutions in France or abroad, or from public or private research centers.
L'archive ouverte pluridisciplinaire HAL, est destinée au dépôt et à la diffusion de documents scientifiques de niveau recherche, publiés ou non, émanant des établissements d'enseignement et de recherche français ou étrangers, des laboratoires publics ou privés. 


\section{Bidirectional transfer of Engrailed homeoprotein across the plasma membrane requires $\mathrm{PIP}_{2}$}

Authors: Irène Amblard ${ }^{1,2}$, Edmond Dupont ${ }^{1}$, Isabel Alves ${ }^{3}$, Julie Miralvès ${ }^{1}$, Isabelle Queguiner ${ }^{1}$, Alain Joliot ${ }^{*}$.

\section{Affiliations:}

${ }^{1}$ Center for Interdisciplinary Research in Biology (CIRB), College de France, CNRS, INSERM, PSL Research University, Paris, France

2 Sorbonne University, Paris, France

${ }^{3}$ CBMN, UMR 5248 CNRS, University of Bordeaux, Pessac, France

*Correspondence to: alain.joliot@college-de-france.fr

Keywords: homeoprotein, unconventional secretion, membrane translocation, PIP2, internalization

Summary Statement: Deciphering the mechanism of homeoprotein intercellular trafficking 


\section{Abstract}

Homeoproteins are a class of transcription factors sharing the unexpected property of intercellular trafficking that confers to homeoproteins a paracrine mode of action. Homeoprotein paracrine action participates to the control of patterning processes, including axonal guidance, brain plasticity and boundary formation. Internalization and secretion, the two steps of intercellular transfer, rely on unconventional mechanisms but the cellular mechanisms at stake still need to be fully characterized. Thanks to the design of new quantitative and sensitive assays dedicated to the study of homeoprotein transfer in HeLa cell culture, we demonstrate a core role of the phosphatidylinositol-4,5-biphosphate $\left(\mathrm{PIP}_{2}\right)$ together with cholesterol in the translocation of Engrailed2 (EN2) homeoprotein across the plasma membrane. Using drug and enzymatic treatments, we show that both secretion and internalization are regulated according to $\mathrm{PIP}_{2}$ levels. The requirement of $\mathrm{PIP}_{2}$ and cholesterol in EN2 trafficking correlates with their selective affinity for this protein in artificial bilayers, which is drastically decreased with a paracrine-deficient mutant of EN2. We propose that the bi-directional plasma membrane translocation events occurring during homeoprotein secretion and internalization respectively are parts of a common process.

\section{Introduction}

The plasma membrane is a pleiotropic structure that preserves cell homeostasis while allowing the exchange of various molecules, including large biological molecules endowed with signaling properties such as proteins. Along this view, the transfer across the plasma membrane constitutes the landmark that characterizes protein internalization and secretion, in opposite directions. In both cases, membrane fusion is the prevalent mechanism, endocytosis for entry and conventional secretion for exit but alternative mechanisms have been proposed. 
Intercellular trafficking of homeoproteins constitute a fascinating example of protein transfer across the plasma membrane. These proteins were originally identified thanks to their role in transcriptional regulation and are defined by the nature of their DNA-binding domain, the homeodomain (Gehring et al., 1994). Some years ago, we have observed that homeoproteins present the unexpected property of transfer between cells (Joliot et al., 1998). Indeed, it was recently reported that most if not all homeoproteins are able to transfer (Lee et al., 2019), also emphasizing the pivotal role of the conserved homeodomain in this process (Sagan et al., 2013). Since the original ex vivo observations, the physiological significance of homeoprotein intercellular trafficking was revealed in several contexts (reviewed in Di Nardo et al., 2018), as it provides to homeoproteins a paracrine mode of action that superimposes on their transcriptional activities. In particular, the paracrine action of Engrailed subclass has been reported in diverse species, including flies, fishes and mice. Targeted inhibition of Engrailed paracrine action, thanks to the use of neutralizing extracellular antibodies, induces local and specific patterning defects in Drosophila (Layalle et al., 2011)and zebrafish (Rampon et al., 2015), or axonal guidance defects (Wizenmann et al., 2009), which in the latter case involved the regulation of local translation by the transferred protein (Stettler et al., 2012).

Understanding the mechanism of homeoprotein intercellular trafficking remains challenging as both secretion and internalization rely on unconventional mechanisms. Homeoproteins are devoid of secretion signal and predominantly reside in the nucleus. However, homeoproteins such as the chick Engrailed2 homeoprotein (EN2) used as a model homeoprotein, shuttles between the nucleus and the cytosol and around $10 \%$ of the intracellular protein pool is secreted in the soluble fraction of the conditioned medium, thus not entrapped within extracellular vesicles (Maizel et al., 1999). In the cytosol, EN2 associates with the membrane fractions enriched in cholesterol and glycosphingolipids (Joliot et al., 1997). In addition to secretion, homeoproteins are internalized when added in the extracellular medium and accumulate in cytosolic and nuclear compartments, even when endocytosis is 
inhibited (Joliot et al., 1991). The aim of our study was to identify at the cellular and molecular levels the mechanism of homeoprotein transfer across the plasma membrane, which occurs in opposite directions during secretion and internalization.

Conventional protein secretion is initiated by the recognition of a short $\mathrm{N}$-terminal secretion sequence through a co-translational process, which drives the translocation of the nascent polypeptide chain into the Endoplasmic Reticulum. In the last decade, unconventional protein secretion (UPS) pathways have been identified, involving distinct mechanisms (Nickel and Rabouille, 2018; Zhang and Schekman, 2013). Four distinct UPS types are now defined (Rabouille, 2017), which differ on the nature (soluble, transmembrane...) and the mode of secretion (plasma membrane translocation, vesicular-based...) of the secreted substrate. Although different UPS can drive the secretion of leaderless cytosolic/nuclear substrate in a free state in the medium, only UPS Type I seems to be constitutive and independent of any specific stimuli, as observed for homeoprotein secretion. UPS Type I refers to soluble proteins that are secreted through direct translocation across the plasma membrane and among them, FGF2 (Schäfer et al., 2004) and HIV Tat (Rayne et al., 2010) are prototypical examples. FGF2 is synthesized as a cytosolic protein but needs to be secreted to activate its extracellular receptors. It is devoid of secretion signal but creates pores within the plasma membrane, driving its secretion (Müller et al., 2015). A critical step in FGF2 secretion is its accumulation at the plasma membrane, which requires its specific interaction with $\mathrm{PIP}_{2}$ (Temmerman et al., 2008), a quantitatively minor but essential component of the plasma membrane inner leaflet (Hammond et al., 2012). A similar requirement for $\mathrm{PIP}_{2}$ was demonstrated for HIV Tat secretion (Rayne et al., 2010). Although functionally and structurally unrelated, Tat and FGF2 proteins share a high content in basic amino acids (pI of 9.8 and 9.5 respectively).

Protein internalization mostly relies on endocytosis, a vesicular-based pathway initiated by invagination from the plasma membrane (Doherty and McMahon, 2009). Consequently, internalized 
proteins remain entrapped within the vesicles and never reach the cytosol. Among exceptions, some bacterial toxins are able to translocate through biological membranes and accumulate in the cytosol (Williams and Tsai, 2016). We also learned from the study of Cell Penetrating Peptides that extracellularly loaded protein or polypeptides could have access to the cytosol, although the efficacy and the mechanism(s) involved remain debated (Kauffman et al., 2015).

In HeLa cells, we have focused our study on the events taking place at the plasma membrane, the actual barrier that separates the intra and extracellular spaces. We demonstrate that, similarly to FGF2 and Tat, EN2 translocates across the plasma membrane during secretion thanks to its interaction with $\mathrm{PIP}_{2}$. Most importantly, reverse translocation during EN2 internalization that also occurs at the plasma membrane exhibits a similar requirement for $\mathrm{PIP}_{2}$, thus revealing striking similarities in their mechanisms.

\section{Results}

\subsection{PIP2 is required for EN2 secretion}

Homeoprotein intercellular trafficking have been best studied with EN2, a polypeptide of $28 \mathrm{kD}$ with a pI of 9.2, it was thus kept for this study. To accurately address the mechanism of protein secretion, we generated stable cell clones in the engineered FlpIn-TREX HeLa line (Tighe et al., 2008) that permits the targeted insertion of the transgene at an invariant site and its inducible expression upon doxycycline addition. Once secreted by EN2 cell clone, EN2 accumulates at the cell surface and can be

detected by flow cytometry (Layalle et al., 2011). We verified that EN2 secretion was insensitive to the classical inhibitor of conventional secretion Brefeldin A but became sensitive upon EN2 fusion to an ectopic secretion signal sequence (ssEN2) (Fig. 1A). FGF2 secretion was also insensitive to Brefeldin A to the same extent as EN2 (Fig. S1A). Once secreted, both proteins interact with cell surface carbohydrates and were released from the cell surface by heparin wash treatment (Fig. 1B). 
The $\mathrm{PIP}_{2}$-interacting drug neomycin efficiently decreases FGF2 secretion (Temmerman et al., 2008). We asked whether it also impaired EN2 secretion. Overnight neomycin treatment inhibited EN2 and FGF2 secretion to similar extent (Fig. 1C), indicating the involvement of $\mathrm{PIP}_{2}$ in EN2 secretion. We then evaluated whether EN2 directly interacts with $\mathrm{PIP}_{2}$ as demonstrated for HIV Tat (Rayne et al., 2010) and FGF2 (Temmerman et al., 2008). The interaction of EN2 recombinant protein with lipid bilayers of controlled composition was analyzed by Plasmon-Waveguide Resonance (PWR) (Harté et al., 2014), a spectroscopic technique allowing to directly measure the interaction and affinity of molecules with membrane lipids organized in the form of a planar lipid membrane. Significant interaction was observed (Fig. 1D) with pure phosphatidylcholine (PC) bilayer (KD:6.3 nM) but incorporation of $\mathrm{PIP}_{2}(10 \%)$ dramatically lowered the $\mathrm{KD}$ to $75 \mathrm{pM}$, compared to the mild effect elicited by addition of phosphatidylserine (PS) (KD:2.8 nM) (Fig. 1E). As expected, the specific interaction between FGF2 and $\mathrm{PIP}_{2}$ was confirmed using the same experimental set-up, although with slightly lower affinity compared to EN2 (Fig. S1B).

We have previously shown that a pool of EN2 associates with the membrane fraction, both in vivo and ex vivo (Joliot et al., 1997). We thus asked whether this association was depending on $\mathrm{PIP}_{2}$ interaction. The membrane fraction of HeLa EN2 or ssEN2 cells clones was incubated with neomycin and the protein released in the medium was separated from membranes by ultracentrifugation. More than $50 \%$ of the EN2 protein was retrieved in the supernatant following neomycin treatment (Fig. 1F), highlighting the involvement of $\mathrm{PIP}_{2}$ in this association. The distribution of FGF2 (Fig. S1C), but neither the ones of ssEN2 nor the endoplasmic reticulum marker calregulin distributions were affected by this treatment, attesting vesicle integrity and consequently, that the EN2 pool sensitive to neomycin was not entrapped within vesicles. 


\subsection{A new assay for the analysis of unconventional secretion}

As $\mathrm{PIP}_{2}$ mostly resides in the inner leaflet of the plasma membrane, we decided to focus on this compartment. Flow cytometry, although quantitative at a single cell level, is poorly informative on the mechanism of secretion. To address this question, we took advantage of the Rush strategy developed by Boncompain et al. (Boncompain et al., 2012), an inducible secretion assay. A secreted substrate fused to a streptavidin binding peptide (SBP) (Wilson et al., 2001) is sequestered by the co-expression of a "hook" protein fused to core streptavidin (Strep). Biotin addition induces the synchronized release of the substrate from the hook and its eventual secretion. Importantly, the subcellular localization of the hook determines the site of release along the secretion pathway of the substrate upon biotin addition. We chose a hook that localizes at the inner side of the plasma membrane, by Strep fusion either with the acylation sequence (aa1-10) of the tyrosine kinase LCK or with the cytosolic tail of a transmembrane protein (TM1). Flow cytometry was not sensitive enough to monitor the secretion burst induced by biotin addition (not shown). We thus implemented our assay with a highly sensitive detection tool (HiBit assay, Promega), based on light production upon spontaneous complementation of two fragments of an engineered Nanoluciferase (Dixon et al., 2016).

To monitor protein secretion, the small 11 aa fragment (HiBiT) was fused to the secreted substrate and the large one (LgBiT) was expressed on the extracellular side plasma membrane upon fusion to the Extracellular domain of the TM1Strep trans-membrane protein. By combining the two strategies (Fig. 2A), secretion of the pool of EN2 sequestered at the cytosolic side of the plasma membrane was measured by the specific increase in light production induced by biotin addition compared to control conditions (without biotin). To minimize non-specific release, stable cell clones were generated for all secreted substrates in FlpIn-TREX HeLa cells. LCK-StrepCherry (hook) was transiently expressed in SBP-Myc-EN2-Hibit (named EN2* for convenience) cell clone. By immunofluorescence we verified on permeabilized cells the retention of EN2* at the plasma membrane 
in transfected cells (white arrows) and its release by biotin addition (Fig. 2B). Concomitantly, EN2* cell surface staining (visualized in non-permeabilized cells) was increased by biotin treatment (Fig. 2C). A similar behavior was observed with the FGF2* cell clone (Fig. S2).

The secretion of three different proteins was then analyzed by luminescence measurements, GFP* and FGF2* being used respectively as negative and positive controls. The sensor/hook (LgBitTM1Strep) was expressed in each clone and following biotin addition together with the luciferase substrate furimazin, the kinetics of secretion was monitored for one hour. Cells were then lysed and the intracellular content for each protein was measured by luminescence for normalization. Subtracting biotin-negative from biotin-positive measurement allowed us to remove the contribution of non-sequestered proteins (e.g. expressed in non-transfected cells). Secretion-induced luminescence started right after biotin addition with $\mathrm{FGF} 2 *$ and $\mathrm{EN} 2 *$ clones, supporting a direct translocation of the intracellular hooked proteins. In the same conditions, no GFP* secretion could be observed (Fig. 2D), thus validating our secretion assay which was named TransRush assay (Rush targeting translocation). We also noticed a higher efficiency of FGF2* secretion compared to EN2*. An additional benefit of our assay is to allow the measurement of secretion on a short time scale, more suitable to analyze the impact of pharmacological treatments while limiting indirect or toxic effects. We first tested the effect of short-time neomycin treatment (added $30 \mathrm{~min}$ before biotin addition) in the TransRush assay. One hour after biotin addition, both EN2* and FGF2* secretions were drastically reduced by neomycin treatment to similar extents, further supporting a direct action of the drug at the site of the plasma membrane (Fig. 2E).

\subsection{PIP2 levels modulate EN2 secretion}

We next asked whether EN2 secretion was sensitive to $\mathrm{PIP}_{2}$ levels, using an enzymatic strategy. OCRL is a 5-phosphatase that dephosphorylates PIP $_{2}$ into PI4P and its ectopic expression drastically 
reduced $\mathrm{PIP}_{2}$ levels, as revealed with anti-PIP 2 antibodies (Fig. 3A). The Cherry-OCRL coding sequence was inserted in a bi-expressor plasmid together with LgBiTM1Strep sequence to maximize co-expression. Cherry-OCRL protein, but not Cherry co-expression, reduced EN2* and FGF2* secretion after biotin addition (Fig. 3B). Conversely, we expressed the PI4P5K1 $\alpha$ enzyme to increase $\mathrm{PIP}_{2}$ levels at the plasma membrane. As shown in Fig. 3C, cells expressing Cherry-PI4P5K showed a consistent concomitant increase of $\mathrm{PIP}_{2}$ levels and EN2* or FGF2* secretion (Fig. 3D). The effect of the enzymatic treatments on EN2 trafficking suggested that PI4P could not substitute for PIP 2 in the process. We thus asked whether the nature of the phospholipid could modulate EN2 interaction. Incorporation of PI4P into PC bilayer increased the affinity for EN2 but to a significantly lower extend (3 folds) compared to $\mathrm{PIP}_{2}$ (Fig. 3E). In comparison, the affinity for FGF2 was drastically reduced as previously reported (Temmerman et al., 2008), suggesting different modes of interaction for the two proteins. Taken together, these results demonstrate the pivotal and highly specific role of $\mathrm{PIP}_{2}$ levels in EN2 unconventional secretion.

\subsection{PIP2 modulates EN2 internalization}

Homeoproteins are not only secreted but are also internalized and reach cytosolic and nuclear compartments. After a one-hour incubation in the culture medium, FITC-labelled recombinant EN2 (FEN2) was mainly detected at the cell surface (Fig. 4A, Ctrl). Addition in the medium of Trypan blue (TB), an efficient quencher of extracellular fluorescence (Vranic et al., 2013), revealed the specific accumulation of intracellular F-EN2 (Fig. 4A, +TB), although impacting signal detection (Fig. S3A). Both punctuate and diffuse distributions were observed, the latter highlighting the cytosolic and nuclear accumulation of the protein. As $\mathrm{PIP}_{2}$ are required for EN2 secretion, we asked whether they would also be involved in the reverse process of internalization. In cells treated with neomycin, F-EN2 intracellular accumulation was drastically reduced (Fig. 4B). Importantly, the extracellular association of F-EN2 with the plasma membrane, detected before trypan blue addition, was not affected by 
neomycin treatment (Fig. S3), supporting an intracellular action of the drug. Next, we tested the effect of $\mathrm{PIP}_{2}$-modulating enzymatic treatments. Hela cells were transfected with Cherry fusion constructs and F-EN2 internalization was compared between transfected (Cherry positive) and non-transfected cells. Cherry-OCRL expression significantly impaired F-EN2 internalization (Fig. 4C). Using the same protocol, Cherry-PI5P4K expression increased F-EN2 internalization (Fig. 4D).

A distinctive feature of plasma membrane translocation-driven processes is the direct access of the internalized protein to the cytosol. We have thus adapted the HiBiT assay to selectively target this mode of internalization. We first added a HiBiT tag to the recombinant EN2 protein (Hb-EN2) and secondly generated a reporter cell clone that expressed the LgBiT protein in the cytosol. Light production only occurs if the $\mathrm{Hb}$-EN2 protein added in the medium reaches the cytosol and can be measured in live cells thanks to the quick diffusion of the luciferase substrate into live cells (Song et al., 2013). One hour after its addition in the extracellular medium, Hb-EN2 efficiently stimulated light production together with the cytosolic reporter (Fig. 4E). As expected, neither Hb-GST nor Hb-FGF2 could activate the reporter. Both neomycin treatment (Fig. 4E) and OCRL ectopic expression (Fig. 4F) lowered the cytosolic accumulation of Hb-EN2, whereas PI4P5K ectopic expression had an opposite enhancing effect (Fig. 4G). 


\subsection{Selective role of raft associated PIP2 in EN2 trafficking}

In a previous study, we have shown that EN2 selectively associates with cholesterol-enriched membranes (Joliot et al., 1997). Using the PWR assay, we demonstrated that cholesterol incorporation in the membrane increased 10 fold EN2 affinity for a $\mathrm{PIP}_{2}$ containing lipid bilayer (Fig. 5A). We then asked whether cholesterol levels directly modulate EN2 intercellular trafficking. Extracting cholesterol from the plasma membrane by methyl-ß-Cyclodextrin (MBCB) treatment reduced F-EN2 internalization (Fig. S4A) and EN2* secretion (Fig. S4B). Due to the reported side-effects of MBCB, alternative strategies were used to deplete plasma membrane cholesterol. Overnight treatment of HeLa cells with U18886A (U18), an inhibitor of cholesterol transport and synthesis (Cenedella, 2009), provoked a drastic depletion of plasma membrane cholesterol, visualized by the removal of the fluorescent D4H cholesterol sensor (Maekawa and Fairn, 2015) from the plasma membrane (Fig. S4C), and strongly impaired both Hb-EN2 internalization (Fig. 5B) and EN2* secretion (Fig. 5C). In conclusion, the two membrane components, $\mathrm{PIP}_{2}$ and cholesterol, are essential to EN2 bi-directional trafficking across the plasma membrane.

$\mathrm{PIP}_{2}$ are known to associate with rafts, the cholesterol enriched membrane domains (Pike and Casey, 1996). We verified that $\mathrm{PIP}_{2}$ co-purified with the raft fraction isolated by density gradient separation of detergent-treated membranes (Fig. S5A). We next asked whether this $\mathrm{PIP}_{2}$ pool was specifically involved in EN2 trafficking. To selectively deplete raft-associated $\mathrm{PIP}_{2}$, we used an assay developed by Varnai et al. (Varnai et al., 2006). It consists in the selective and conditional membrane targeting of a cytosolic TypeIV-5Phosphatase fragment (5Dom) that has retained its catalytic activity thanks to the ability of LCK and SRC acylation motifs to target proteins towards raft and non-raft domains respectively (Fig. S5B and Varnai et al., 2006). Rapamycin is known to promote dimerization of two protein modules, FRB (FKBP binding domain of mTOR) and FKBP (Stockwell and Schreiber, 1998). A 5Dom-FRB-Cherry fusion was co-expressed with a FKBP-CFP protein fused to either LCK 
or SRC acylation motif and rapamycin addition induced its relocation according to the localization of the co-expressed acylation motif (Fig. 5D). Both LCK and SRC motifs promoted plasma membrane targeting of 5Dom and $\mathrm{PIP}_{2}$ level decrease (Fig. 5D), but only raft-targeted 5Dom (with LCK motif) significantly impaired F-EN2 internalization (Fig. 5E). By contrast, non-raft $\mathrm{PIP}_{2}$ depletion induced a small increase in EN2 internalization (Fig. 5F). Such depletion was previously shown to increase the raft-associated PIP 2 pool (Johnson et al., 2008). We concluded that cholesterol and the raft associated $\mathrm{PIP}_{2}$ pool cooperate to regulate EN2 intercellular trafficking.

\subsection{Competing for PIP $P_{2}$ interaction in live cells}

Several protein domains are known to selectively interact with PIP $_{2}$ and therefore, they have been used to probe $\mathrm{PIP}_{2}$ in live cells. The most widely used PIP2 biding-domain is the Pleckstrin homology domain of Phospholipase C $\partial 1$ (PHPLC) (Várnai and Balla, 1998). HIV Tat, whose secretion also depends on $\mathrm{PIP}_{2}$, efficiently delocalizes a GFP-PHPLC sensor from the plasma membrane (Rayne et al., 2010). We thus decided to follow the behavior of GFP-PHPLC during EN2 trafficking by measuring the plasma membrane/cytosol index of GFP-PHPLC (see method section). EN2 uptake quickly induced a delocalization of GFP-PHPLC probe toward the cytosol (Fig. 6A), but not that of a Cherry protein fused to the LCK acylation sequence (LCK-Cherry) which remained at the plasma membrane (Fig. S6A). Redistribution started only few minutes after EN2 addition and increased with time (Fig. 6B) We then asked if EN2 secretion also promotes PHPLC delocalization. GFP-PHPLC was expressed in the TransRush assay. Promoting EN2* secretion by biotin addition induced a delocalization of GFP-PHPLC towards the cytosol similarly to EN2 internalization (Fig. 6C). The distribution of LCK-Cherry remained unmodified in the same conditions (Fig. S6B). These results further confirm that $\mathrm{PIP}_{2}$ is an essential relay in EN2 translocation across the plasma membrane in either direction. Using the same experimental protocol, FGF2* secretion also delocalized GFP-PHPLC 
upon biotin addition (Fig. 6D) but had little effect when applied in the extracellular medium, in agreement with its inability to enter cells by direct translocation (Fig. 4E).

\subsection{A paracrine-deficient mutant of Engrailed has a reduced affinity for PIP2}

Intercellular transfer confers to homeoproteins a paracrine mode of action which contribute to homeoprotein physiological functions (Di Nardo et al., 2018). In zebrafish embryo, we have shown recently that the paracrine activity of ectopically expressed EN2 protein induces eye defects (Rampon et al., 2015). We have characterized a paracrine-deficient mutant of EN2 (EN2 $\left.{ }_{\mathrm{ww}>\mathrm{KK}}\right)$, unable to induce such phenotype and strongly impaired in its intercellular trafficking. We first confirmed the altered behavior of the EN2 $2_{\mathrm{ww}>\mathrm{KK}}$ mutant with our assays. Both internalization (Fig. 7A) and secretion (Fig. 7B) were significantly impaired. Additionally, the EN2 ${ }_{\mathrm{ww}>\mathrm{KK}}$ mutant was unable to delocalize PHPLC in either situation (Fig. 7C, D). We thus asked whether the interaction of $\mathrm{EN} 2_{\mathrm{ww}>\mathrm{KK}}$ with $\mathrm{PIP} \mathrm{P}_{2}$ was concomitantly affected by the mutation. Compared to the wild type EN2 protein, the affinity of $\mathrm{EN} 2_{\mathrm{ww}>\mathrm{KK}}$ mutant for a pure PC-containing membrane (KD:20 nM) was not significantly reduced but a high impact was observed with membrane containing PIP $_{2}$ with an almost 30 fold decrease in affinity (KD:2.5 nM) compared to the wild-type protein(Fig. 7E). These results further support the pivotal role of $\mathrm{PIP}_{2}$ interaction not only in EN2 trafficking but also in the paracrine activity of the protein. 


\section{Discussion}

In the present study, we have investigated the molecular and cellular mechanisms of homeoprotein intercellular transfer, focusing on the mechanism of plasma membrane crossing. The two events of crossing, occurring during secretion and internalization respectively, have been analyzed separately in this study. Combining Rush and HibiT assays in a new TransRush assay, we demonstrate that a pool of EN2 that has reached the inner side of the plasma membrane is secreted by direct translocation towards the extracellular medium. We further demonstrate the specific interaction of EN2 with $\mathrm{PIP}_{2}$ and its pivotal role in secretion. First, the extent of secretion strictly correlates with $\mathrm{PIP}_{2}$ levels, modulated either by enzymatic treatments or drugs. Secondly, EN2 competes for PIP 2 binding with PHPLC2 when secreted. EN2 is a new example of $\mathrm{PIP}_{2}$-dependent secreted substrate along with FGF2 and HIV Tat, both synthesized in the cytosol and highly basic. EN2 secretion would thus relies on a UPS Type I pathway, although the mechanism of translocation across the acyl part of the bilayer remains to be clarified. Using a dedicated assay that selectively targets the cytosolic accumulation of the internalized protein, we show here that this mode of internalization shares with secretion a very same requirement for $\mathrm{PIP}_{2}$ and cholesterol, strongly suggesting that these two events are part of a same process. Both involve the translocation of the protein across the plasma membrane but in two opposite directions. EN2 secretion and internalization would thus result in a dynamic equilibrium between the two sides of the plasma membrane, which depends, at least in part, on the local micro-environment at the two membrane interfaces.

Soluble proteins that translocate across the plasma membrane encounter distinct environments, the hydrophilic cytosol and the hydrophobic core of the bilayer. At the plasma membrane, FGF2 and Tat proteins assemble into oligomers which enable the formation of pores (Müller et al., 2015; Zeitler et al., 2015). We have no evidence of multimer formation in the case of EN2 which in addition, possesses only one cysteine residue. Importantly, in the presence of negatively charged lipid bicelles, 
the conformation of EN2 protein analyzed by NMR is shifted in a way that promotes the exposure of the hydrophobic core of the homeodomain and its insertion into the acyl part of the bilayer (Carlier et al., 2013). Indeed, bilayer interaction with EN2 not only relies on electrostatic interactions because it is increased by cholesterol addition and reduced with the $\mathrm{EN} 2_{\mathrm{ww}>\mathrm{KK}}$ mutant that has two less aromatic residues and two more basic ones. The bilayer organization might also be required as PHPLC, which interact almost exclusively with the polar head of $\mathrm{PIP}_{2}$ (Watt et al., 2002), efficiently binds to $\mathrm{PIP}_{2}$ beads whereas neither EN2 (or FGF2) could do so (Fig. S7). The interplay between electrostatic and hydrophobic interactions with $\mathrm{PIP}_{2}$, shown to promotes oligomer formation in the case of FGF2 (Steringer et al., 2012), might act as a hub for EN2 to exchange between the cytosol and the bilayer. At this stage, we cannot ruled-out the participation of additional components in the translocation process. For instance, ABC transporters (UPS Type II) mediate the secretion of acylated peptides in yeast (Kuchler et al., 1993) and recently,

Bidirectional translocation of EN2 across the plasma membrane occurs despite the asymmetrical composition of this structure. $\mathrm{PIP}_{2}$ mostly resides in the cytosolic leaflet of the membrane but its translocation to the exofacial leaflet has been reported through an ABCA1-dependent mechanism (Gulshan et al., 2016) and might participate to EN2 trafficking. Interestingly, unconventional secretion and translocation of annexin 2 and 5 depend on the phospholipid scramblase TMEM 16F, even in basal conditions (Stewart et al., 2018). From the extracellular side, mirroring the "hub" function of PIP 2 inside the cell, other components might initiate EN2 translocation and in particular, glycosaminoglycans (GAGs). First, they are essential determinants of homeoprotein uptake in vivo (Beurdeley et al., 2012), and of homeoprotein-derived peptide uptake ex vivo (Jiao et al., 2009). They are also indispensable to FGF2 secretion (Zehe et al., 2006). Due to their flexibility, these long chains of negatively charged sugars might not only concentrate EN2 at the cell surface, playing the role of 
recruiting platforms, but also bring the protein in close proximity of the exofacial leaflet and possibly favor its insertion in the bilayer.

Although critical to understand the whole process, plasma membrane translocation of EN2 constitutes only one step along EN2 intercellular transfer. Within the cell, EN2 has to be addressed to the plasma membrane in order to be secreted and conversly, internalized EN2 should be able to escape the plasma membrane to exert its intracellular functions. For the first point, we (Maizel et al., 1999) and others (Zhou et al., 2012) have shown in previous works that secreted homeoprotein originates from the nucleus because secretion requires the nuclear export of the protein. Intriguingly, nuclear accumulation and secretion are strictly correlated in an ex-vivo model of intercellular transfer (Tassetto et al., 2005), suggesting an instructive role of the nucleus in the process. A similar correlation was reported for Galectin-3 (Gong et al., 1999). One can note that polyphosphoinositides, including PIP $_{2}$, are also found within the nucleoplasm and their interaction with nuclear proteins can regulate nucleocytoplasmic translocation events (Jacobsen et al., 2019). Once in the cytosol, EN2 addressing to the plasma membrane might involves specific association with intracellular vesicles and/or posttranslational modifications as reported for EN2 (Maizel et al., 2002).

How internalized EN2 could spread into the cytosol despite its strong interaction with PIP2. At this stage, we can only speculate on the mechanism at stake, but two hypotheses are favored. The first hypothesis involves the participation of cytosolic partners that would compete with PIP2 for EN2 interaction. The second one is based on the study of lipid transfer proteins that convey various lipids between two membrane compartments. Binding/release cycles rely on intramolecular conformational switches that regulate the accessibility of the phospholipid binding motif within the protein (Wong et al., 2017).

The paracrine mode of action of homeoprotein is the functional outcome of their trafficking property. First demonstrated with selected homeoproteins (Di Nardo et al., 2018), a recent study now 
shows that intercellular trafficking is common to most if not all homeoproteins (Lee et al., 2019) and consequently, that paracrine functions might be a shared property of the entire protein family. The reduced affinity of the paracrine-deficient mutant $\mathrm{EN} 2_{\mathrm{ww}>\mathrm{KK}}$ for $\mathrm{PIP}_{2}$ might reveal a new physiological role of $\mathrm{PIP}_{2}$ as a generic regulator of homeoprotein trafficking. Because $\mathrm{PIP}_{2}$ levels regulate multiple cellular processes, from cell morphology and cytoskeleton dynamics to second messenger production, their specific requirement in UPS Type I might create a bridge between this pathway and the physiological state of the cell.

\section{Methods}

\subsection{Cell culture}

Cell culture experiments were performed on HeLa cells grown in DMEM supplemented with 10\% fetal bovine serum. Transient transfections were performed with Lipofectamine 2000 (Life Technologies) according to the manufacturer's instructions. Cells were cultured for an additional $24 \mathrm{~h}$ before being processed for analysis. Stable clones were generated for each protein used in the secretion assays. All cell clones were produced in a modified HeLa cell line (HeLa FlpIn-TREX) kindly provided by S. Taylor (Tighe et al., 2008) according to the instructions of the FlpIn-TREX Core Kit (Invitrogen) and are listed in Table S3. Briefly, the cell line allows the targeted insertion of the transgene by co-expression of the FlpIn recombinase as well as its inducible expression by doxycycline when using appropriate promoter thanks to the constitutive expression of the tetracycline repressor. Cells were checked routinely for the absence of mycoplasma contamination (MycoAlert, Lonza).

\subsection{Chemicals and Pharmacological treatments}

All drugs and Chemicals were purchased at Sigma unless specified. To inhibit conventional protein secretion, protein expression was induced for $4 \mathrm{~h}$ with doxycycline before addition of $10 \mu \mathrm{g} / \mathrm{ml}$ 
Brefeldin A for 2 additional hours. Wash-out of cell-surface associated proteins was performed by incubation with $10 \mathrm{mg} / \mathrm{ml}$ Heparin for $5 \mathrm{~min}$ followed by 2 washes with PBS. To reduce PIP 2 accessibility, cells were pre-treated with $10 \mathrm{mM}$ neomycin. For cholesterol extraction experiments,

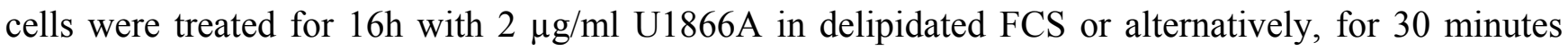
with $10 \mathrm{mM}$ methyl-B-cyclodextrin. Membrane targeting of 5Dom using FKBP/FRB conditional heterodimerization was performed by treatment with $100 \mathrm{nM}$ rapamycin for 30 minutes.

\subsection{Immunocytochemistry}

Cells grown on coverslips were fixed with paraformaldehyde (4\%, $10 \mathrm{~min}$, room temperature) in PBS, permeabilized or not with Triton X-100 (0.3\%, 5 min, room temperature) and saturated with PBS containing $10 \%$ FCS before incubation with primary antibodies ( $1 \mathrm{~h}$, room temperature) and Alexalabeled secondary antibodies (Thermo 1:500, $1 \mathrm{~h}$, room temperature). Signal levels were adjusted independently of permeabilized and unpermeabilized conditions because of significant differences in signal intensity (higher under permeabilized conditions).

EN2* and FGF2* were revealed with a polyclonal anti-myc antibody (Sigma C3956, $5 \mu \mathrm{g} / \mathrm{ml}$ ) followed by secondary antibody staining (AlexaFluor488 donkey anti rabbit IgG 1/400).

PIP2 was performed according to (Hammond et al., 2009). Cells grown on coverslips were washed in PBS and fixed (PBS, 4\% PFA, 0.25\% glutaraldehyde) for 15 minutes at RT and then on ice for $1 \mathrm{~h}$. All subsequent steps were performed on ice. After 3 washes (PBS, $\mathrm{NH}_{4} \mathrm{Cl} 50 \mathrm{mM}, 15$ minutes each), saturation was proceeded in Buffer A (20mM Pipes, $137 \mathrm{mM}$ sodium chloride, $2.8 \mathrm{mM}$ potassium chloride. $\mathrm{pH}$ 6.8) supplemented with $0.5 \%$ Saponin and 5\% FCS for 2h. Primary antibody (anti-PIP2, 2C11, Echelon, $5 \mu \mathrm{g} / \mathrm{ml}$ in Buffer A, 0.1\% Saponin, 2\% FCS) was added for $2 \mathrm{~h}$ or overnight. After

three washes (Buffer A, 0.1\% Saponin), secondary antibody (AlexaFluor488 donkey anti mouse IgM 1/400, Life Technologies in Buffer A, 0.1\% Saponin 2\% FCS) was performed. Coadded for $1 \mathrm{~h}$. 
Coverslips were then washed three times (Buffer A, 0.1\% Saponin) before post-fixation with PFA 2\% in Buffer A (15 minutes on ice and then 10 minutes at RT). After rinsing with water, coverslips were dried and mounted.

\subsection{Internalization}

Cells (30,000 per well) were plated on $\mu$-slide six-well plates (Ibidi). After $24 \mathrm{~h}$, the medium was removed and cells were incubated with the fluorescent protein $(1 \mu \mathrm{M})$ diluted in DMEM for 30 minutes at $37^{\circ} \mathrm{C}$ before visualization. Cells were analyzed either directly to visualize the cell-surface staining or following addition of Trypan Blue ( $0.1 \%$ final concentration), an efficient quencher of all extracellular fluorescence and a marker of permeabilized cells, to visualize only the intracellular staining in live cells.

\subsection{DNA constructs and recombinant proteins}

All DNA constructs used in this study are listed in Table S2-3 and available upon request.

His6-tagged recombinant proteins were produced in BL21 (DE3) grown in MagicMedia (Invitrogen) $24 \mathrm{~h}, 28^{\circ} \mathrm{C}$ and purified on HisTrap columns (GE Healthcare) by Imidazole gradient elution on AKTA Prime according to manufacturer instructions. Following tag removal by incubation with PreScisson protease $\left(6 \mathrm{~h}, 4^{\circ} \mathrm{C}\right)$, the protein was purified on Heparin column (GE Healthcare), eluted by $\mathrm{NaCl}$ gradient elution and dialyzed for 2 days $(20 \mathrm{mM}$ phosphate buffer, $100 \mathrm{mM} \mathrm{NaCl}, \mathrm{pH}$ 7.5). For protein labelling, $100 \mu \mathrm{M}$ of dialyzed purified protein was incubated with a twofold molar excess of fluorescein isothiocyanate in labeling buffer ( Carbonate buffer $50 \mathrm{mM} \mathrm{pH} \mathrm{9.5,} 100 \mathrm{mM}$ $\mathrm{NaCl})$ overnight at $4^{\circ} \mathrm{C}$ and free FITC was removed by dialysis $\left(48 \mathrm{~h}, 4^{\circ} \mathrm{C}, 20 \mathrm{mM}\right.$ phosphate buffer, $100 \mathrm{mM} \mathrm{NaCl}, \mathrm{pH}$ 7.5). The efficacy of FITC incorporation was controlled by SDS-PAGE and spectral analysis. The FITC:protein molecular ratio was estimated between 1.5 and 2 for all proteins. 


\subsection{Quantitative Secretion assay}

Cells (13,000 per well) were plated on 96-well plates (Greiner Bio-one) coated with $1.5 \mu \mathrm{g} / \mathrm{ml}$ PolyDL-ornithine and induced for protein expression with doxycycline $(1 \mu \mathrm{g} / \mathrm{ml})$. After $10 \mathrm{~h}$, cells were transfected with the indicated plasmids and cultured for $24 \mathrm{~h}$. The medium was then replaced with fresh medium in the incubator and protein release was induced by biotin addition (100 $\mu \mathrm{M}$ final) and following Furmazin (Promega, 1/500) addition, luciferase activity was measured $1 \mathrm{~h}$ later on a plate reader (Tristar, Berthold). Cells were then lysed in the presence of recombinant $\operatorname{LgBiT}(0.7 \mu \mathrm{M}$ final concentration) and Furimazin to measure intracellular protein expression. Rush-specific secretion was calculated by subtracting biotin-treated with biotin-untreated (control) wells for each condition and normalization with intracellular protein expression.

\subsection{Quantitative Internalization assay}

Cells $(90,000$ per well) were plated on 24 -well culture dishes. After $24 \mathrm{~h}$, the protein was added to the medium and incubated for 30 minutes at $37^{\circ} \mathrm{C}$. Following to washes with PBS, cells were collected by centrifugation after Trypsin treatment $(0.25 \%$ final concentration) and resuspended in PBS $2 \%$ serum. Furimazin (1/500) was added to live cells and luciferase activity of the internalized protein was measured on a plate reader (Tristar, Berthold). 


\subsection{PHPLC delocalization assay}

HeLa cells were co-transfected with GFP-PHPLC and LCK-Cherry expression plasmids, PHPLC delocalization was visualized in live cells, following either biotin addition in the Trans-Rush assay or direct addition of the indicated protein in the medium. The kinetic of PHPLC delocalization was more accurate on time lapse image acquisition from a same cell, but equivalent results were obtained with images acquired at different time points on different cells. Delocalization index was calculated as followed.

Index is set at $100 \%$ at $\mathrm{t}=0$

\subsection{Imaging}

Most of the Images of fixed / live cells were obtained with . A CSU-W1 Yokogawa spinning disk coupled to a Zeiss Axio observer Z1 inverted microscope or CSUX1-A1 equipped with a sCMOS Hamamatsu camera and a $63 \times(1.4$ Oil; WD:0.17mm $)$ objective. Alternatively, a CSUX1-A1 Yokogawa spinning disk coupled to a Zeiss Axio observer Z1Nikkon Ti Eclipse inverted microscope equipped with a Evolve EMCCD camera (Roper) and a $63 \times(1.45$ Oil; WD:0.17mm) objective was used. 


\subsection{Cell Fractionation}

Cells were lysed by Dounce homogenization in hypotonic lysis buffer (Hepes 10mM, KCl $10 \mathrm{mM}, \mathrm{MgCl}_{2} 3 \mathrm{mM}$, EGTA $1 \mathrm{mM}$, Protease inhibitors) subsequently adjusted to $0.25 \mathrm{M}$ Sucrose. Following nuclei removal $(1,000 \mathrm{~g}, 10 \mathrm{~min})$, membranes were pelleted by centrifugation $(150,000 \mathrm{~g}, 30$ min) and washed with sucrose lysis buffer before being pelleted by a second round of centrifugation. Membrane pellet was resuspended in Sucrose Lysis buffer and treated or not with freshly prepared neomycin (10 mM final concentration) $30 \mathrm{~min}$ at $4^{\circ} \mathrm{C}$. Membrane samples were diluted 10 folds in sucrose lysis buffer and released and membrane-associated proteins were separated by centrifugation $(150,000 \mathrm{~g}, 30 \mathrm{~min})$. Pellets were resuspended directly in Laemmli buffer and supernatant proteins were precipitated $\left(0.02 \%\right.$ Deoxycholate, $4 \% \mathrm{TCA}, 30$ min à $\left.4^{\circ} \mathrm{C}\right)$ before resuspension in Laemmli buffer in order to load equivalent fractions of each sample on SDS PAGE.

Raft separation was performed as described in (Yamaguchi et al., 2009). Briefly, Cells extracts were resuspended in (Hepes $10 \mathrm{mM}, \quad \mathrm{KCl} 10 \mathrm{mM}, \mathrm{MgCl}_{2} 3 \mathrm{mM}$, EGTA $1 \mathrm{mM}, \quad 0.25 \mathrm{M}$ saccharose, $1 \%$ Brij-35, Protease inhibitors) incubated on ice for $15 \mathrm{~min}$ and sonicated. The Post nuclear supernatant was adjusted to 35\% Optiprep and loaded at the bottom of a 5-30\% Optiprep gradient and centrifuged $(250,000 \mathrm{~g}, 2 \mathrm{~h}) .10$ fractions (1-Light, 10-Heavy) were collected and processed for western blot analysis. 


\subsection{PWR}

Self-assembled planar lipid bilayers used for PWR experiments were obtained from spontaneous fusion of a $3 \mathrm{mg} / \mathrm{mL}$ solution of small unilamellar liposomes (SUVs) composed of egg PC, egg PC/DOPS (3/1 mol/mol), egg PC/PIP 2 (9/1 mol $/ \mathrm{mol})$ and egg PC/cholesterol $/ \mathrm{PIP}_{2}(7 / 2 / 1 \mathrm{~mol} / \mathrm{mol} / \mathrm{mol})$ into the silica surface of the PWR sensor (prism). PWR assays were performed by using a homemade PWR instrument (Harté et al., 2014). Light was generated from a polarized CW laser (He-Ne; wavelength of $632.8 \mathrm{~nm})$ incident on the back surface of a thin metal film (Ag) deposited on a glass prism and coated with a layer of $\mathrm{SiO} 2$. The spectral angular resolution was $\leq 1 \mathrm{mdeg}$. PWR spectra corresponding to plots of reflected light intensity versus incident angle was excited with light whose electric vector was either parallel (s-polarized) or perpendicular (p-polarized) to the plane of the resonator surface. After formation and stabilization of the lipid bilayer (no further spectral changes with time), the protein was incrementally added to the PWR cell sample. Spectral changes were acquired for both polarizations. The system was let to equilibrate before each peptide addition. PWR being sensitive to the optical properties of material deposited on the resonator surface (so peptide bound to the lipid bilayer), interference from the material present in the bulk solution (non-bound) is unlikely. Apparent dissociation constants (KD) were obtained by plotting the resonance minimum position as a function of the peptide concentration and by fitting the plot through a hyperbolic binding function using GraphPad Prism ${ }^{\mathrm{TM}}$ version 5.0a (GraphPad Software, San Diego, California, US). Binding data for both $p$ - and $s$-polarized light are presented, that characterize binding affinity along the two membrane axes (perpendicular and parallel to the membrane, respectively). The binding affinities obtained from the two axes are usually quite comparable, which is the case also here. 


\subsection{Statistical Analysis}

Data were analyzed with GraphPad Prism 6 and expressed as the mean +/- SEM. Two groups were compared with student's t-test. For multiple group comparison, one-way analysis of variance (ANOVA) followed by Tukey's post-tests was performed. P-values $<0.05$ were considered to be statistically significant.

$$
{ }^{*} \mathrm{p}<0.05 ; * * \mathrm{p}<0.01 ; * * * \mathrm{p}<0.001 ; * * * * \mathrm{p}<0.0001
$$

ssAcknowledgments: We thank S.Taylor for providing us with the FLpIn-TREX HeLa cell line. and A. Echard for providing with plasmids and S. Vriz and M. Volovitch for fruitful discussions and careful rereading of the manuscript. We gratefully acknowledge the College de France imaging facility (IMACHEM-IBiSA), member of the French National Research Infrastructure France-BioImaging (ANR-10-INBS-04), which received support from XXX and from the program «Investissements d'Avenir» ANR-10-LABX-54 MEMOLIFE".

Competing interests: The authors declare no competing interests.

Funding: This work supported by CNRS, INSERM, Collège de France, Université de Paris, Labex PSL Memolife and Agence Nationale de la Recherche, (ANR-17-CE11-0050). 


\section{References}

Beurdeley, M., Spatazza, J., Lee, H. H. C., Sugiyama, S., Bernard, C., Di Nardo, A. A., Hensch, T. K. and Prochiantz, A. (2012). Otx2 binding to perineuronal nets persistently regulates plasticity in the mature visual cortex. J. Neurosci. Off. J. Soc. Neurosci. 32, 9429-9437.

Boncompain, G., Divoux, S., Gareil, N., de Forges, H., Lescure, A., Latreche, L., Mercanti, V., Jollivet, F., Raposo, G. and Perez, F. (2012). Synchronization of secretory protein traffic in populations of cells. Nat. Methods 9, 493-498.

Carlier, L., Balayssac, S., Cantrelle, F.-X., Khemtémourian, L., Chassaing, G., Joliot, A. and Lequin, O. (2013). Investigation of homeodomain membrane translocation properties: insights from the structure determination of engrailed-2 homeodomain in aqueous and membrane-mimetic environments. Biophys. J. 105, 667-678.

Cenedella, R. J. (2009). Cholesterol Synthesis Inhibitor U18666A and the Role of Sterol Metabolism and Trafficking in Numerous Pathophysiological Processes. Lipids 44, 477-487.

Di Nardo, A. A., Fuchs, J., Joshi, R. L., Moya, K. L. and Prochiantz, A. (2018). The Physiology of Homeoprotein Transduction. Physiol. Rev. 98, 1943-1982.

Dixon, A. S., Schwinn, M. K., Hall, M. P., Zimmerman, K., Otto, P., Lubben, T. H., Butler, B. L., Binkowski, B. F., Machleidt, T., Kirkland, T. A., et al. (2016). NanoLuc Complementation Reporter Optimized for Accurate Measurement of Protein Interactions in Cells. ACS Chem. Biol. 11, 400-408. Doherty, G. J. and McMahon, H. T. (2009). Mechanisms of endocytosis. Annu. Rev. Biochem. 78, 857-902.

Gehring, W. J., Affolter, M. and Bürglin, T. R. (1994). Homeodomain proteins. Annu. Rev. Biochem. 63, 487-526.

Gong, H. C., Honjo, Y., Nangia-Makker, P., Hogan, V., Mazurak, N., Bresalier, R. S. and Raz, A. (1999). The NH2 terminus of galectin-3 governs cellular compartmentalization and functions in cancer cells. Cancer Res. 59, 6239-6245.

Gulshan, K., Brubaker, G., Conger, H., Wang, S., Zhang, R., Hazen, S. L. and Smith, J. D. (2016). PI(4,5)P2 Is Translocated by ABCA1 to the Cell Surface Where It Mediates Apolipoprotein A1 Binding and Nascent HDL Assembly. Circ. Res. 119, 827-838.

Hammond, G. R. V., Balla, T., Fischer, M. J., Anderson, K. E., Holdich, J., Koteci, A. and Irvine, R. F. (2012). PI4P and PI(4,5)P2 Are Essential But Independent Lipid Determinants of Membrane Identity. Sci. N. Y. NY 337, 727-730.

Harté, E., Maalouli, N., Shalabney, A., Texier, E., Berthelot, K., Lecomte, S. and Alves, I. D. (2014). Probing the kinetics of lipid membrane formation and the interaction of a nontoxic and a toxic amyloid with plasmon waveguide resonance. Chem. Commun. Camb. Engl. 50, 4168-4171.

Jacobsen, R. G., Mazloumi Gavgani, F., Edson, A. J., Goris, M., Altankhuyag, A. and Lewis, A. E. (2019). Polyphosphoinositides in the nucleus: Roadmap of their effectors and mechanisms of interaction. Adv. Biol. Regul. 72, 7-21.

Jiao, C. Y., Delaroche, D., Burlina, F., Alves, I. D., Chassaing, G. and Sagan, S. (2009).

Translocation and endocytosis for cell-penetrating peptide internalization. J. Biol. Chem. 284, 3395733965.

Johnson, C. M., Chichili, G. R. and Rodgers, W. (2008). Compartmentalization of phosphatidylinositol 4,5-bisphosphate signaling evidenced using targeted phosphatases. J. Biol. Chem. 283, 29920-29928.

Joliot, A., Triller, A., Volovitch, M., Pernelle, C. and Prochiantz, A. (1991). alpha-2,8-Polysialic 
acid is the neuronal surface receptor of antennapedia homeobox peptide. New Biol. 3, 1121-1134. Joliot, A., Trembleau, A., Raposo, G., Calvet, S., Volovitch, M. and Prochiantz, A. (1997). Association of Engrailed homeoproteins with vesicles presenting caveolae-like properties. Dev. Camb. Engl. 124, 1865-1875.

Joliot, A., Maizel, A., Rosenberg, D., Trembleau, A., Dupas, S., Volovitch, M. and Prochiantz, A. (1998). Identification of a signal sequence necessary for the unconventional secretion of Engrailed homeoprotein. Curr. Biol. CB 8, 856-863.

Kauffman, W. B., Fuselier, T., He, J. and Wimley, W. C. (2015). Mechanism Matters: A Taxonomy of Cell Penetrating Peptides. Trends Biochem. Sci. 40, 749-764.

Kuchler, K., DohIman, H. G. and Thorner, J. (1993). The a-factor transporter (STE6 gene product) and cell polarity in the yeast Saccharomyces cerevisiae. J. Cell Biol. 120, 1203-1215.

Layalle, S., Volovitch, M., Mugat, B., Bonneaud, N., Parmentier, M.-L., Prochiantz, A., Joliot, A. and Maschat, F. (2011). Engrailed homeoprotein acts as a signaling molecule in the developing fly. Dev. Camb. Engl. 138, 2315-2323.

Lee, E. J., Kim, N., Park, J. W., Kang, K. H., Kim, W.-I., Sim, N. S., Jeong, C.-S., Blackshaw, S., Vidal, M., Huh, S.-O., et al. (2019). Global Analysis of Intercellular Homeodomain Protein Transfer. Cell Rep. 28, 712-722.e3.

Maizel, A., Bensaude, O., Prochiantz, A. and Joliot, A. (1999). A short region of its homeodomain is necessary for engrailed nuclear export and secretion. Dev. Camb. Engl. 126, 3183-3190.

Maizel, A., Tassetto, M., Filhol, O., Cochet, C., Prochiantz, A. and Joliot, A. (2002). Engrailed homeoprotein secretion is a regulated process. Dev. Camb. Engl. 129, 3545-3553.

Müller, H.-M., Steringer, J. P., Wegehingel, S., Bleicken, S., Münster, M., Dimou, E., Unger, S., Weidmann, G., Andreas, H., García-Sáez, A. J., et al. (2015). Formation of Disulfide Bridges Drives Oligomerization, Membrane Pore Formation and Translocation of Fibroblast Growth Factor 2 to Cell Surfaces. J. Biol. Chem. 290, 8925-8937.

Nickel, W. and Rabouille, C. (2018). Unconventional protein secretion: Diversity and consensus. Semin. Cell Amp Dev. Biol. 83, 1-2.

Pike, L. J. and Casey, L. (1996). Localization and turnover of phosphatidylinositol 4,5-bisphosphate in caveolin-enriched membrane domains. J. Biol. Chem. 271, 26453-26456.

Rabouille, C. (2017). Pathways of Unconventional Protein Secretion. Trends Cell Biol. 27, 230-240.

Rampon, C., Gauron, C., Lin, T., Meda, F., Dupont, E., Cosson, A., Ipendey, E., Frerot, A., Aujard, I., Le Saux, T., et al. (2015). Control of brain patterning by Engrailed paracrine transfer: a new function of the Pbx interaction domain. Dev. Camb. Engl. 142, 1840-1849.

Rayne, F., Debaisieux, S., Yezid, H., Lin, Y.-L., Mettling, C., Konate, K., Chazal, N., Arold, S. T., Pugnière, M., Sanchez, F., et al. (2010). Phosphatidylinositol-(4,5)-bisphosphate enables efficient secretion of HIV-1 Tat by infected T-cells. EMBO J. 29, 1348-1362.

Sagan, S., Burlina, F., Alves, I. D., Bechara, C., Dupont, E. and Joliot, A. (2013). Homeoproteins and homeoprotein-derived peptides: going in and out. Curr. Pharm. Des. 19, 2851-2862.

Schäfer, T., Zentgraf, H., Zehe, C., Brügger, B., Bernhagen, J. and Nickel, W. (2004).

Unconventional secretion of fibroblast growth factor 2 is mediated by direct translocation across the plasma membrane of mammalian cells. J. Biol. Chem. 279, 6244-6251.

Song, G., Jiang, Q., Xu, T., Liu, Y.-L., Xu, Z.-G. and Guo, Z.-Y. (2013). A convenient luminescence assay of ferroportin internalization to study its interaction with hepcidin. FEBS J. 280, 1773-1781.

Steringer, J. P., Bleicken, S., Andreas, H., Zacherl, S., Laussmann, M., Temmerman, K., Contreras, F. X., Bharat, T. A. M., Lechner, J., Müller, H.-M., et al. (2012). Phosphatidylinositol 4,5-bisphosphate $(\mathrm{PI}(4,5) \mathrm{P} 2)$-dependent oligomerization of fibroblast growth factor 2 (FGF2) triggers the formation of a lipidic membrane pore implicated in unconventional secretion. J. Biol. Chem. 287, 27659-27669. 
Stettler, O., Joshi, R. L., Wizenmann, A., Reingruber, J., Holcman, D., Bouillot, C., Castagner, F., Prochiantz, A. and Moya, K. L. (2012). Engrailed homeoprotein recruits the adenosine A1 receptor to potentiate ephrin A5 function in retinal growth cones. Dev. Camb. Engl. 139, 215-224.

Stewart, S. E., Ashkenazi, A., Williamson, A., Rubinsztein, D. C. and Moreau, K. (2018).

Transbilayer phospholipid movement facilitates the translocation of annexin across membranes. J. Cell Sci. 131,

Stockwell, B. R. and Schreiber, S. L. (1998). Probing the role of homomeric and heteromeric receptor interactions in TGF- $\beta$ signaling using small molecule dimerizers. Curr. Biol. 8, 761-773.

Tassetto, M., Maizel, A., Osorio, J. and Joliot, A. (2005). Plant and animal homeodomains use convergent mechanisms for intercellular transfer. EMBO Rep. 6, 885-890.

Temmerman, K., Ebert, A. D., Müller, H.-M., Sinning, I., Tews, I. and Nickel, W. (2008). A direct role for phosphatidylinositol-4,5-bisphosphate in unconventional secretion of fibroblast growth factor 2. Traffic Cph. Den. 9, 1204-1217.

Tighe, A., Staples, O. and Taylor, S. (2008). Mps1 kinase activity restrains anaphase during an unperturbed mitosis and targets Mad2 to kinetochores. J. Cell Biol. 181, 893-901.

Várnai, P. and Balla, T. (1998). Visualization of phosphoinositides that bind pleckstrin homology domains: calcium- and agonist-induced dynamic changes and relationship to myo-[3H]inositol-labeled phosphoinositide pools. J. Cell Biol. 143, 501-510.

Varnai, P., Thyagarajan, B., Rohacs, T. and Balla, T. (2006). Rapidly inducible changes in phosphatidylinositol 4,5-bisphosphate levels influence multiple regulatory functions of the lipid in intact living cells. J. Cell Biol. 175, 377-382.

Vranic, S., Boggetto, N., Contremoulins, V., Mornet, S., Reinhardt, N., Marano, F., BaezaSquiban, A. and Boland, S. (2013). Deciphering the mechanisms of cellular uptake of engineered nanoparticles by accurate evaluation of internalization using imaging flow cytometry. Part. Fibre Toxicol. 10, 2.

Watt, S. A., Kular, G., Fleming, I. N., Downes, C. P. and Lucocq, J. M. (2002). Subcellular localization of phosphatidylinositol 4,5-bisphosphate using the pleckstrin homology domain of phospholipase C delta1. Biochem. J. 363, 657-666.

Williams, J. M. and Tsai, B. (2016). Intracellular trafficking of bacterial toxins. Curr. Opin. Cell Biol. 41, 51-56.

Wilson, D. S., Keefe, A. D. and Szostak, J. W. (2001). The use of mRNA display to select highaffinity protein-binding peptides. Proc. Natl. Acad. Sci. U. S. A. 98, 3750-3755.

Wizenmann, A., Brunet, I., Lam, J. S. Y., Sonnier, L., Beurdeley, M., Zarbalis, K., WeisenhornVogt, D., Weinl, C., Dwivedy, A., Joliot, A., et al. (2009). Extracellular Engrailed participates in the topographic guidance of retinal axons in vivo. Neuron 64, 355-366.

Wong, L. H., Čopič, A. and Levine, T. P. (2017). Advances on the Transfer of Lipids by Lipid Transfer Proteins. Trends Biochem. Sci. 42, 516-530.

Yamaguchi, H., Yamaguchi, H., Shiraishi, M., Shiraishi, M., Fukami, K., Tanabe, A., IkedaMatsuo, Y., Ikeda Matsuo, Y., Naito, Y., Naito, Y., et al. (2009). MARCKS regulates lamellipodia formation induced by IGF-I via association with PIP2 and beta-actin at membrane microdomains. $J$. Cell. Physiol. 220, 748-755.

Zehe, C., Engling, A., Wegehingel, S., Schäfer, T. and Nickel, W. (2006). Cell-surface heparan sulfate proteoglycans are essential components of the unconventional export machinery of FGF-2. Proc. Natl. Acad. Sci. U. S. A. 103, 15479-15484. 
Zeitler, M., Steringer, J. P., Müller, H.-M., Mayer, M. P. and Nickel, W. (2015). HIV-Tat Protein Forms Phosphoinositide-dependent Membrane Pores Implicated in Unconventional Protein Secretion. J. Biol. Chem. 290, 21976-21984.

Zhang, M. and Schekman, R. (2013). Cell biology. Unconventional secretion, unconventional solutions. Sci. N. Y. NY 340, 559-561.

Zhou, J., Qin, L., Tien, J. C.-Y., Gao, L., Chen, X., Wang, F., Hsieh, J.-T. and Xu, J. (2012).

$\mathrm{Nkx} 3.1$ functions as para-transcription factor to regulate gene expression and cell proliferation in noncell autonomous manner. J. Biol. Chem. 287, 17248-17256. 
Figures
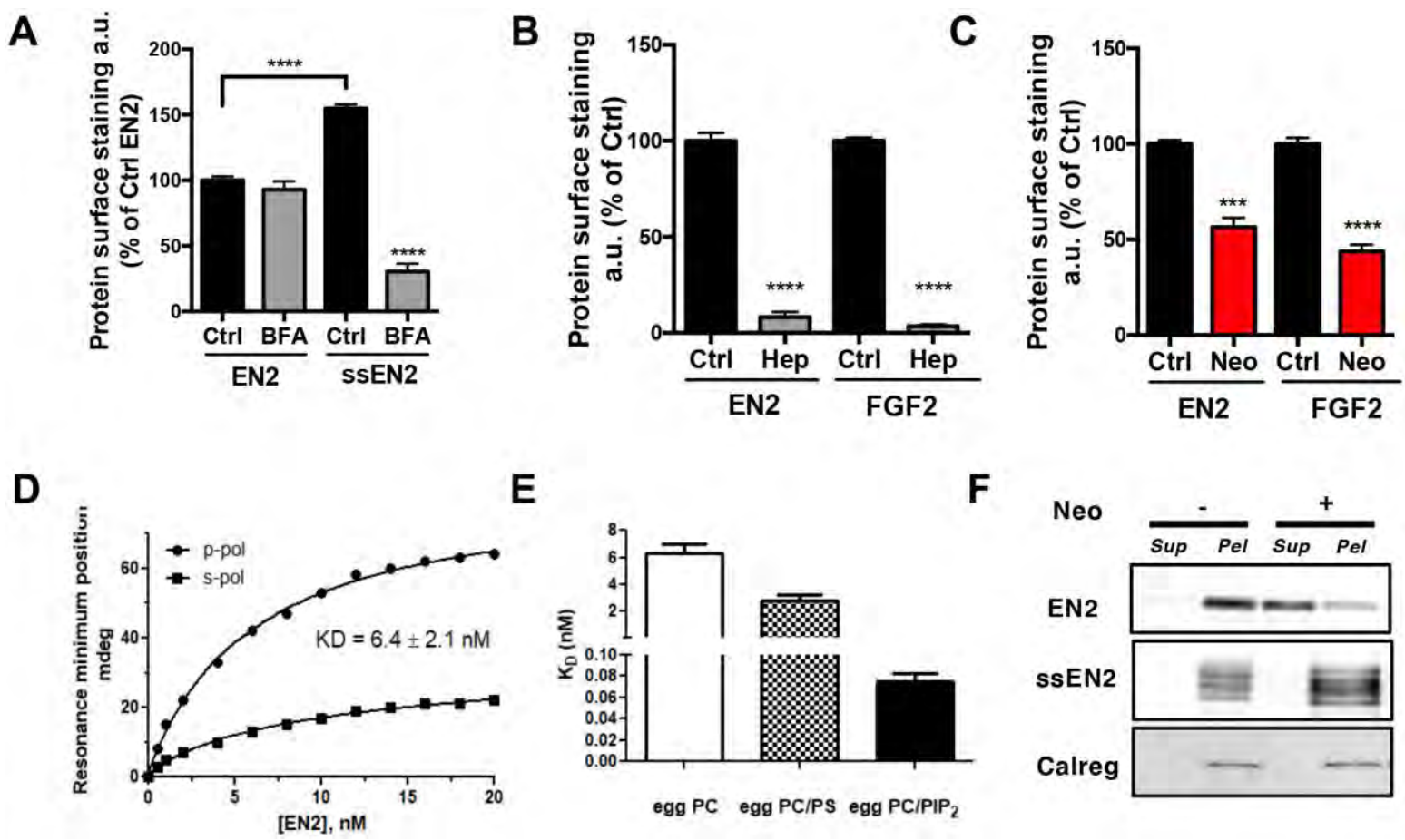

E
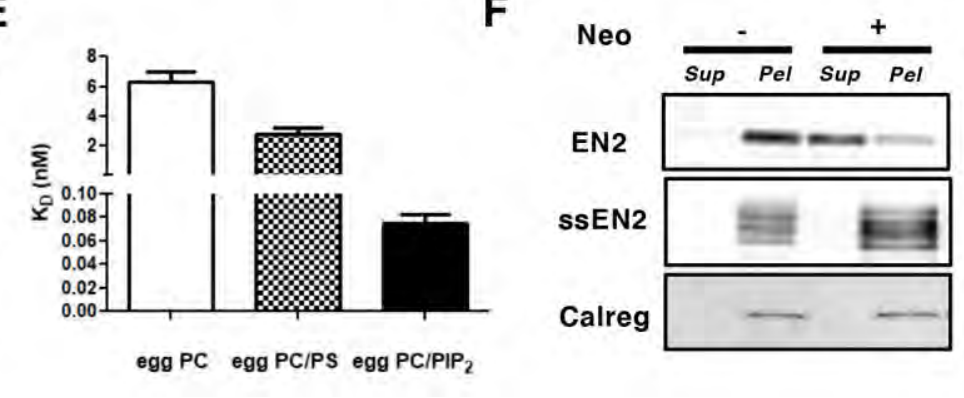

Figure 1: PIP2 is required for EN2 unconventional secretion and enhances lipid membrane affinity

(A) Cell surface accumulation of EN2 or ssEN2 treated or not with Brefeldin A (BFA) for $2 \mathrm{~h}(\mathrm{n}=$ 8; $\mathrm{p}<0,0001$ (Ctrl) ; $<<0,0001$ (ssEN2) by one-way ANOVA followed by Tukey's post-tests). (B) Cell surface removal of EN2 or FGF2 following heparin treatment (Hep) for $5 \min (n=6 ; p<0,0001$ (FGF2 and EN2) by one-way ANOVA followed by Tukey's post-tests). (C) Cell surface accumulation of EN2 or FGF2 in the presence or not of $10 \mathrm{mM}$ neomycin (Neo) for $18 \mathrm{~h}(\mathrm{n}=6 ; \mathrm{p}=0,0005$ (EN2) ; $<<0,0001$ (FGF2) by one-way ANOVA followed by Tukey's post-tests). (D,E) Interaction of EN2 with artificial planar lipid bilayers composed of egg PC, egg PC/DOPS (3/1 mol/mol) and egg PC/PIP $2(9 / 1 \mathrm{~mol} / \mathrm{mol})$ measured by PWR. Each experiment was repeated 3 times. (D) Changes in the minimum resonance 
position for both $\mathrm{p}(\bullet)$ and $\mathrm{s}(\boldsymbol{\bullet})$ polarized time as a function of concentration of EN2 from which KD values have been determined. (E) KD of EN2 interaction ( $n=3$; PC vs PC/PS $p=0,0001$; PC vs PC/PIP2 $\mathrm{p}<0,0001 ;$ PC/PS vs PC/PIP2 $\mathrm{p}=0,0008$ by one-way ANOVA followed by Tukey's post-tests). (F) Western blot analysis of the release of EN2, ssEN2 and calregulin from the membrane fraction treated or not with $10 \mathrm{mM}$ neomycin. Once separated by centrifugation, equivalent fractions of supernatant (Sup) and Pellet (Pel) fractions were analyzed. 


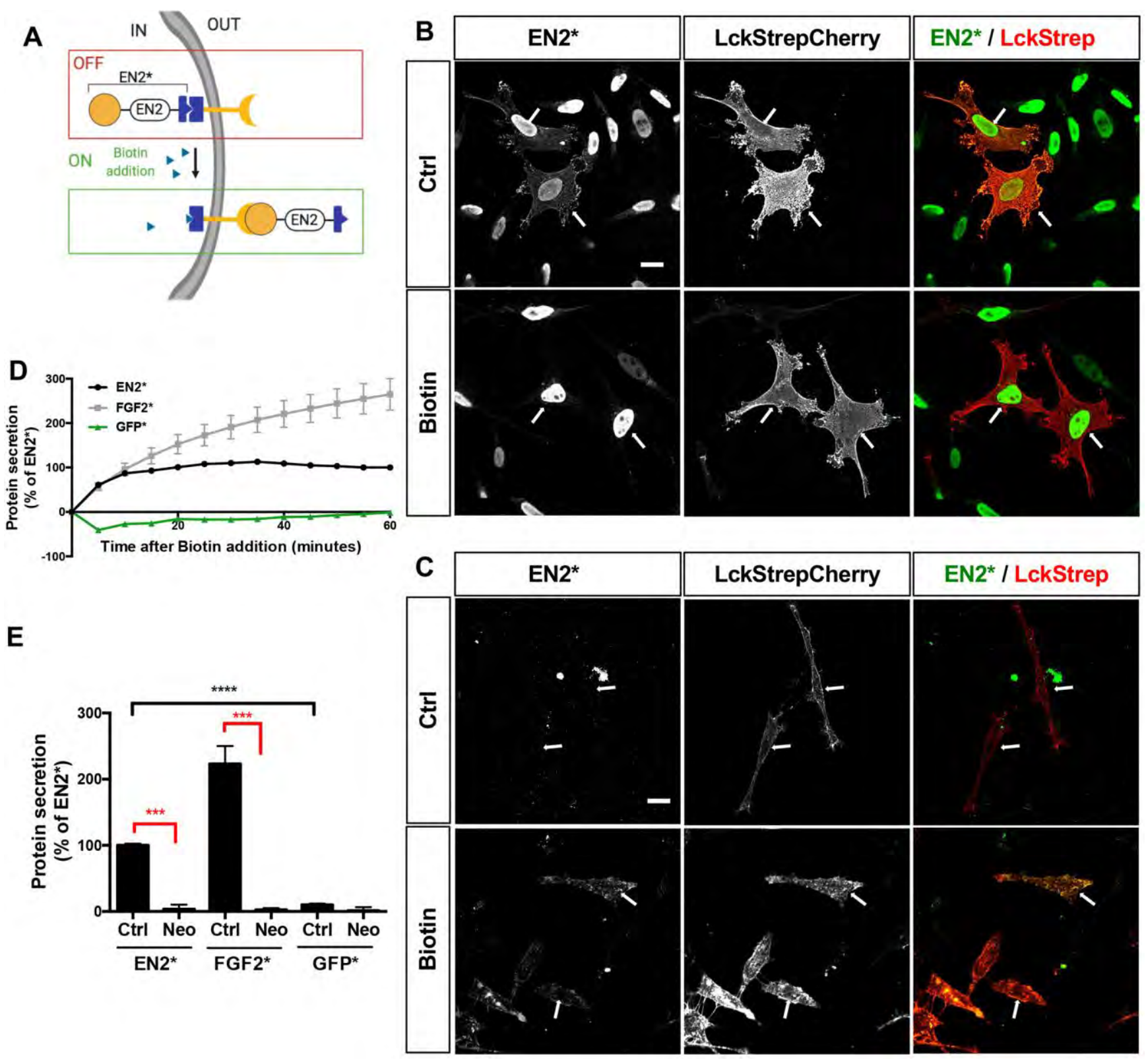

Figure 2: Assessing EN2 unconventional secretion

(A) Principle of the TransRush assay for measuring EN2 secretion based on the combination of RUSH (SBP/streptavidin) and HiBit (Hibit/LgBit) assays. (B, C) EN2* cell clone was transfected with a LCKStrepCherry construct and treated or not with biotin (60 min, $100 \mu \mathrm{M})$. (B) Intracellular or (C) extracellular EN2* was detected by immunofluorescence using anti-myc antibody (green) in 
permeabilized or unpermeabilized conditions respectively together with Cherry staining (red). (D) Kinetics of biotin-induced secretion of EN2* (black), FGF2* (grey) and GFP* (green) proteins. (E) Quantification of EN2*, FGF2* and GFP* protein secretion in cells treated (Neo) or not (Ctrl) with neomycin $(10 \mathrm{mM})$ for 1 hour ( $\mathrm{n}=12 ; \mathrm{p}<0,0001$ (FGF2 and EN2) by one-way ANOVA followed by Tukey's post-tests). Bar: $20 \mu \mathrm{m}$ 
A

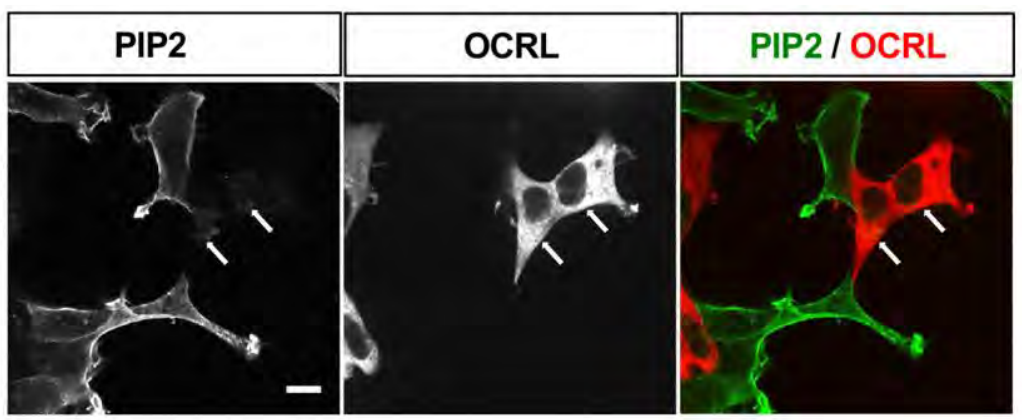

C

E

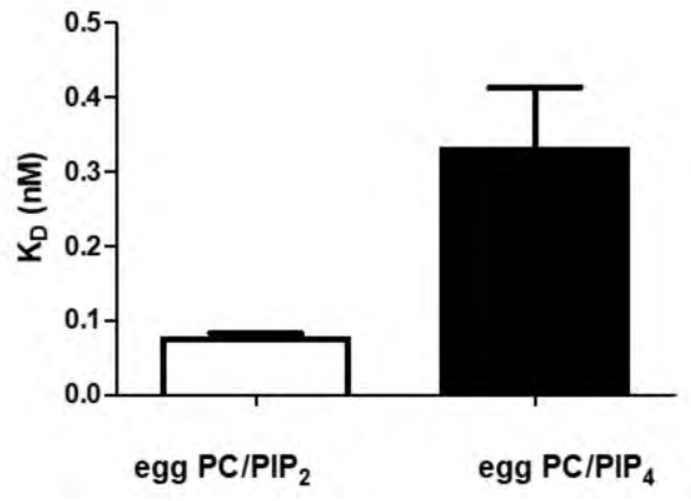

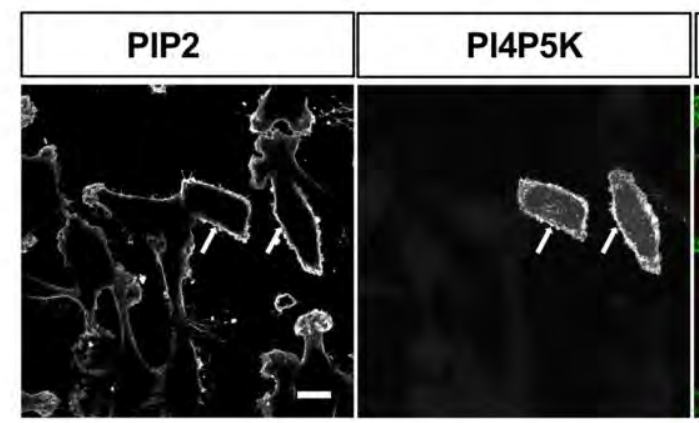

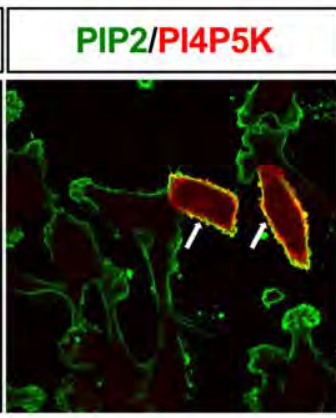

F
B

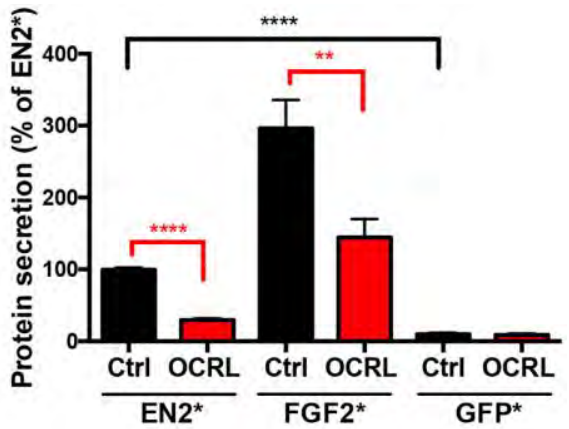

D

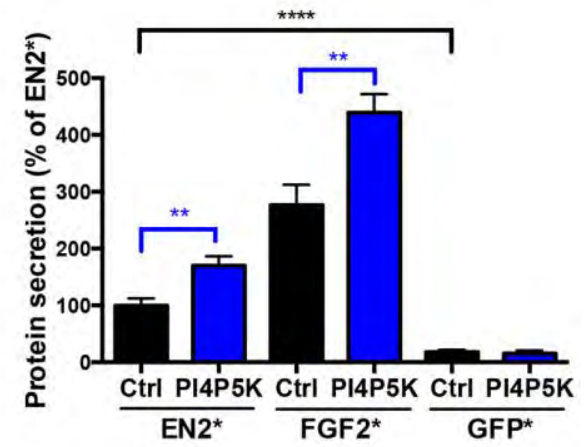

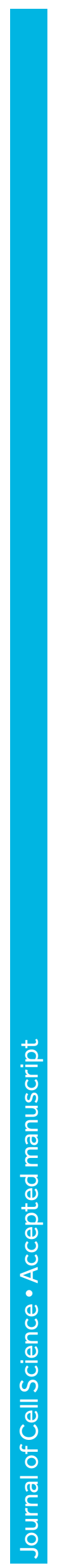

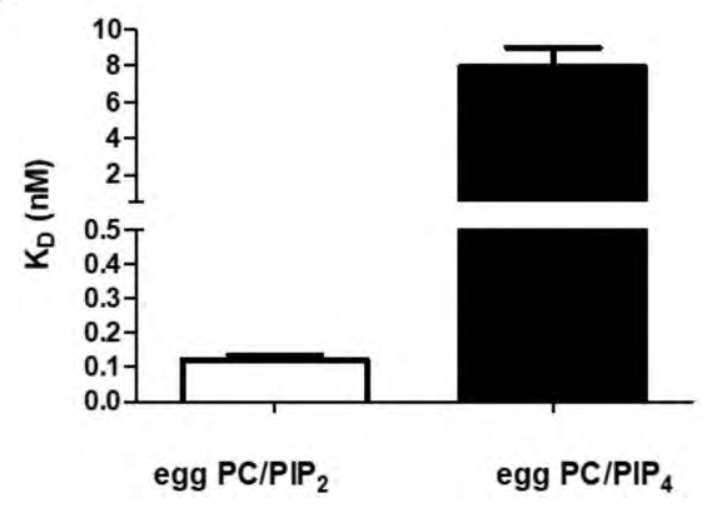

Figure 3: PIP2 directly modulates the kinetics of EN2 and FGF2 secretion

(A) Immunostaining of $\mathrm{PIP}_{2}$ (green) in cells expressing CherryOCRL (red, arrow). (B) Quantification of biotin induced EN2*, FGF2* and GFP* protein secretion in cells expressing Cherry (Ctrl) or CherryOCRL (OCRL), measured 1 hour after biotin addition ( $n=8 ; p<0,0001$ (EN2); $p=0,0063$ (FGF2) by one-way ANOVA followed by Tukey's post-tests). (C) Immunostaining of PIP2 (green) in cells expressing Cherry-PI4P5K (red, arrow). (D) Quantification of biotin-induced EN2*, FGF2* and GFP* protein secretion in cells expressing Cherry (Ctrl) or Cherry-PI4P5K (PI4P5K), measured 1 hour after biotin addition $(\mathrm{n}=8 ; \mathrm{p}=0,0018$ (EN2); $\mathrm{p}=0,0045$ (FGF2) by one-way ANOVA followed by 
Tukey's post-tests). (E, F) Interaction of EN2(E) or FGF2 (F) with artificial planar lipid bilayers composed of egg PC/PI4P (9/1 mol/mol), measured by PWR (Data from Fig. 1E and Fig. S1B are indicated for comparison, $\mathrm{n}=3 ; \mathrm{p}=0,034$ for EN2; 0,017 for FGF2 by Student's t-test). Bar: $20 \mu \mathrm{m}$ 

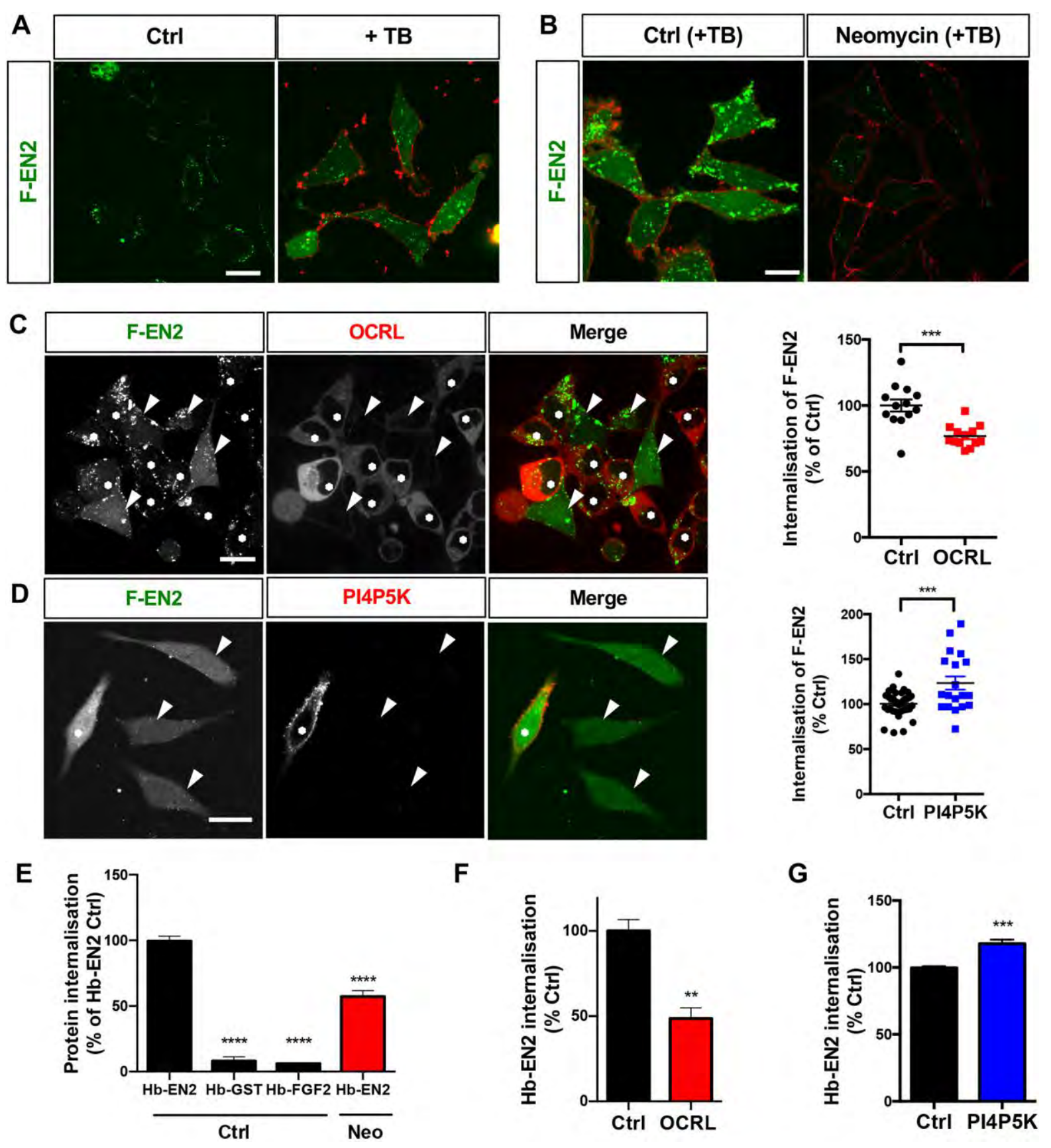

Figure 4: PIP2 modulate EN2 internalization

(A) F-EN2 $(2 \mu \mathrm{M})$ staining in live cells following 1 hour incubation before $(\mathrm{Ctrl})$ or after $(+\mathrm{TB})$ trypan blue addition ( $0.1 \%$ final concentration). Intrinsic trypan blue fluorescence is visualized (red). (B) Intracellular F-EN2 $(2 \mu \mathrm{M})$ staining in live cells after 1 hour incubation in the presence (Neomycin) or absence (Ctrl) of $10 \mathrm{mM}$ after TB addition. (C, D) Intracellular F-EN2 $(2 \mu \mathrm{M})$ staining following 1 hour incubation in live cells expressing (C) Cherry-OCRL ( $n=13 ; p=0,0001$ by Student's t-test) or (D) 
Cherry-PI4P5K ( $n=19 ; \mathrm{p}=0,0004$ by Student's t-test) after TB addition. Diffuse staining intensity is quantified in cells expressing $\left(^{*}\right)$ or not (arrowhead) the respective enzymes (E-G) Luminescencebased quantification of $\mathrm{Hb}-\mathrm{EN} 2, \mathrm{Hb}-\mathrm{FGF} 2$ and $\mathrm{Hb}-\mathrm{GST}$ internalization following 1 hour incubation with cells, (E) treated or not with $10 \mathrm{mM}$ neomycin $(\mathrm{Neo})(\mathrm{n}=4 ; \mathrm{p}<0,0001$, by one-way ANOVA followed by Tukey's post-tests), or expressing (F) CherryOCRL ( $n=4 ; p=0,0014$ by Student's t-test) or (G) Cherry PI4P5K ( $n=6 ; p=0,0002$ by Student's t-test). Cherry expressing cells (Ctrl) were used as a control in (F) and (G). Bar: $20 \mu \mathrm{m}$ 
A

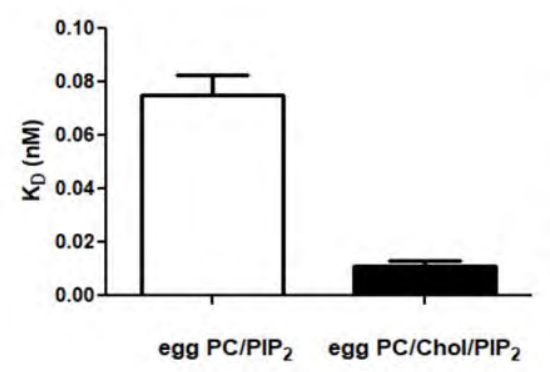

B

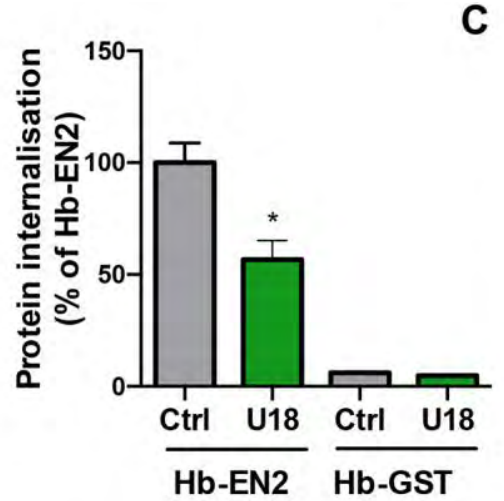

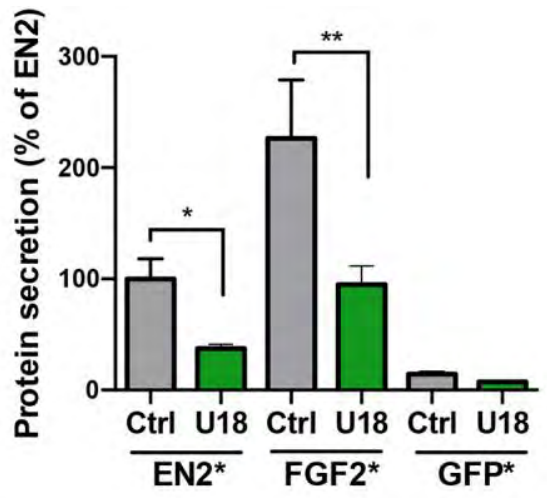

D

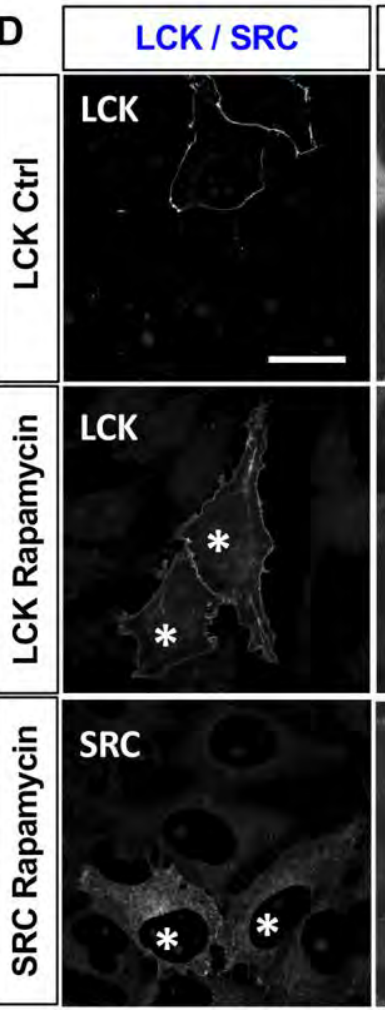

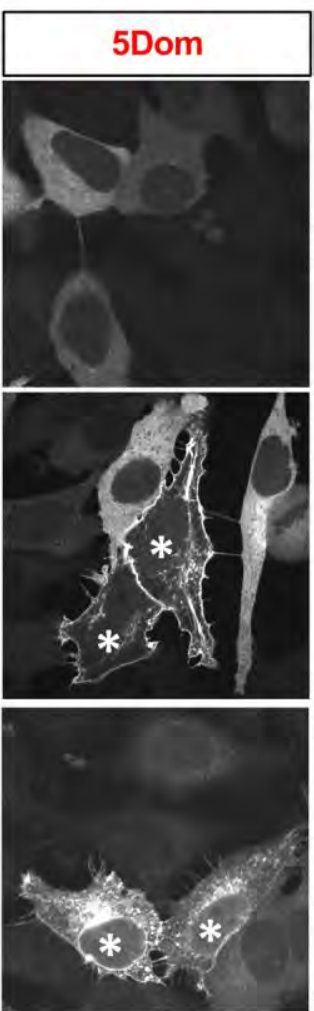
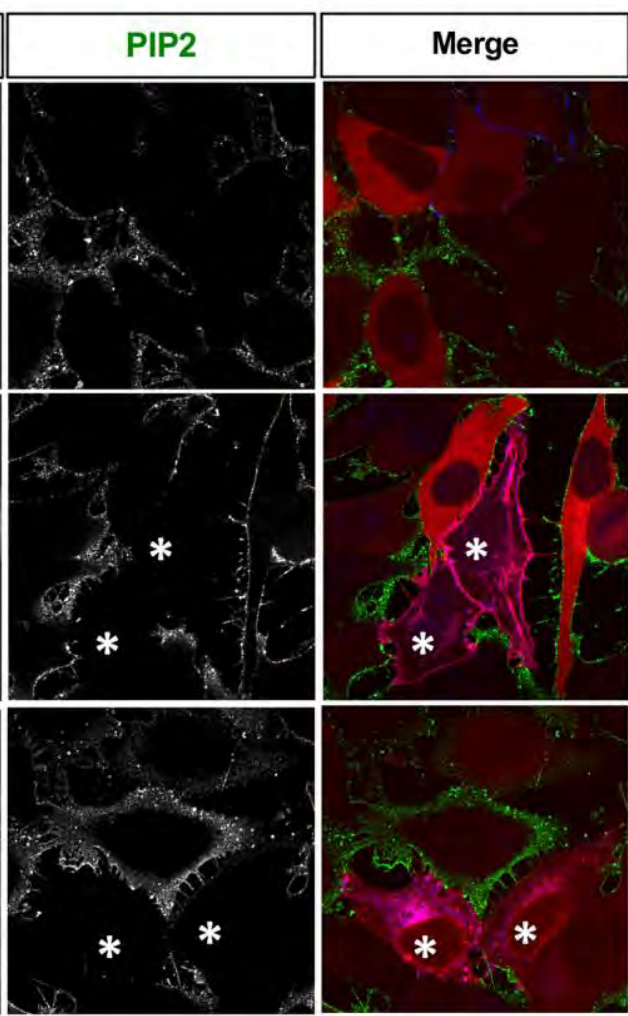

E

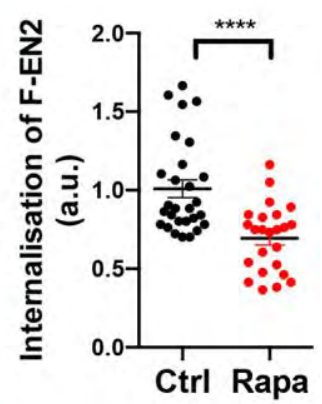

$\mathbf{F}$

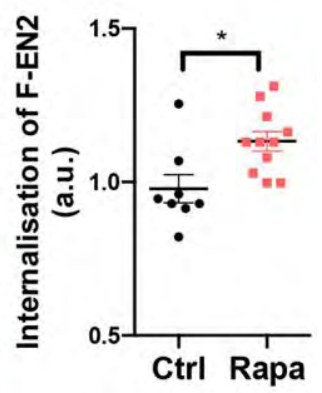

Figure 5: Role of Cholesterol and raft-associated PIP $_{2}$ in EN2 trafficking

(A) Interaction and affinity of EN2 with planar artificial lipid bilayer composed of egg PC/chol/PIP $2(7 / 2 / 1 \mathrm{~mol} / \mathrm{mol} / \mathrm{mol})$ determined by PWR (Data from Fig. 1E are indicated for comparison, $\mathrm{n}=3$; $\mathrm{p}=0,0002$ by Student's t-test). (B) Quantification of biotin-induced EN2*, FGF2* and GFP* protein secretion in cells pre-treated with $2 \mu \mathrm{g} / \mathrm{mL}$ U18666A (U18) for $16 \mathrm{~h}$ or not (ctrl) ( $\mathrm{n}=4 ; \mathrm{p}=0,0161$ (EN2); $\mathrm{p}=0,0036$ (FGF2) by one-way ANOVA followed by Tukey's post-tests). (C) Luminescence-based quantification of $\mathrm{Hb}-\mathrm{EN} 2, \mathrm{Hb}$ - and $\mathrm{Hb}$-GST internalization following one hour 
incubation with cells pre-treated with $2 \mu \mathrm{g} / \mathrm{mL}$ U18666A (U18) for $16 \mathrm{~h}$ or not (ctrl) ( $\mathrm{n}=4$; $\mathrm{p}=0,0142$ (EN2); $\quad \mathrm{p}=0,1011$ (GST) by one-way ANOVA followed by Tukey's post-tests). (D) Immunofluorescence detection of $\mathrm{PIP}_{2}$ (green) in cells co-expressing FKBP-Cherry5Dom (red) and CFP-FRB fused to SRC or LCK anchor in cells treated (Rapamycin) or not (ctrl) with rapamycin 100nM for 30 min. (E, F) Quantification of F-EN2 intracellular staining in cells co-expressing FKBPCherry5Dom and CFP-FRB fused to (E) LCK ( $n=24 ; p<0,0001$ by Student's t-test) or (F) SRC (n=8; $\mathrm{p}=0,011$ by Student's t-test) anchor and treated or not with $100 \mathrm{nM}$ rapamycin for 30 min (Rapa). Bar: $20 \mu \mathrm{m}$ 

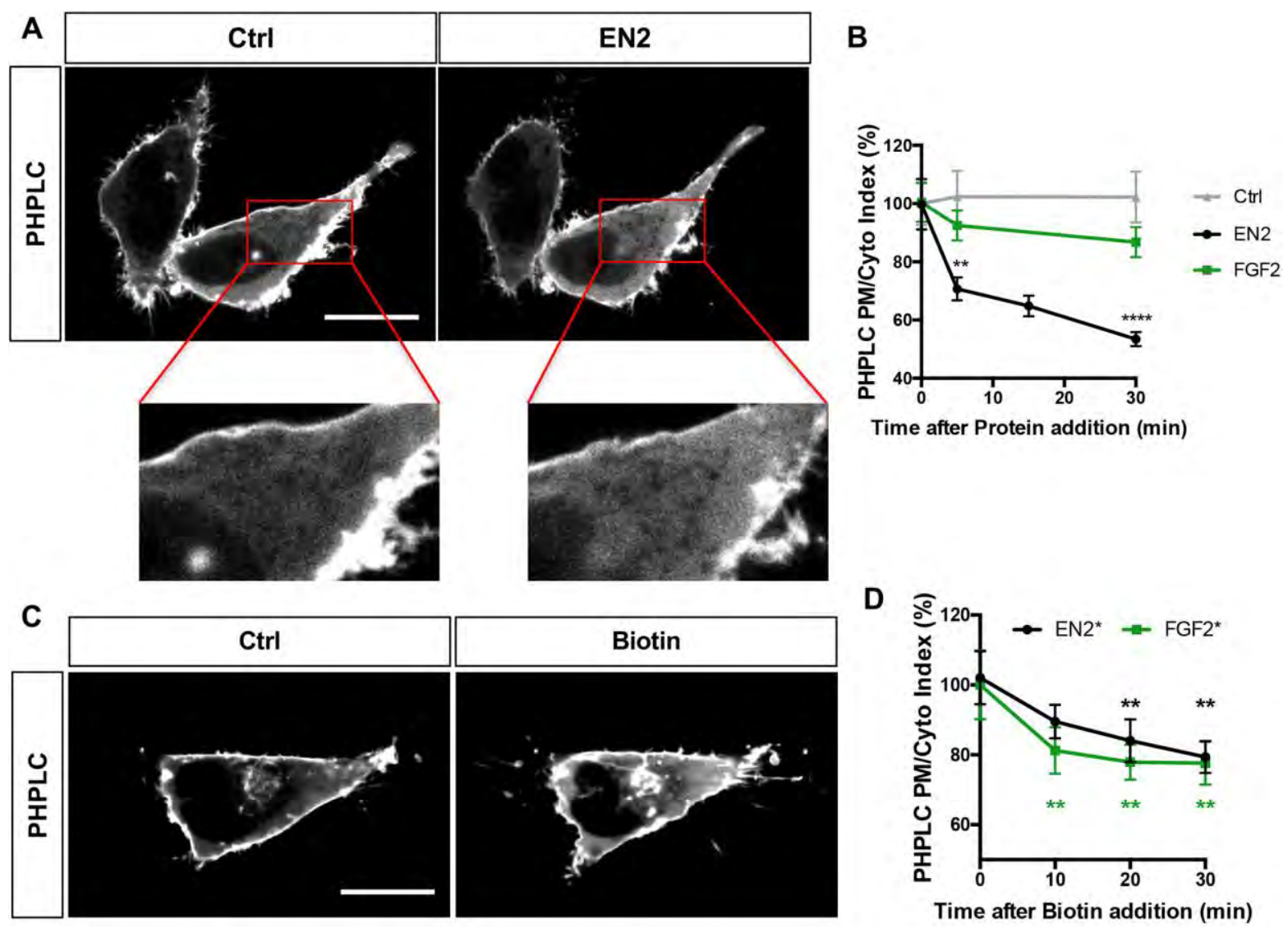

Figure 6: EN2 trafficking induces PHPLC delocalization

(A) PHPLC-GFP distribution in cells before (ctrl) and after (EN2) incubation of extracellular 2 $\mu \mathrm{M}$ EN2 protein for 30 min. (B) Kinetics of PHPLC delocalization following addition of $2 \mu \mathrm{M}$ EN2 or FGF2 proteins ( $\mathrm{n}>14$; Ctrl vs EN2 $\mathrm{p}=0,0031$ at 5 minutes and $\mathrm{p}<0,0001$ at 30 minutes; Ctrl vs FGF2 $\mathrm{p}=0,5125$ at 5 minutes and $\mathrm{p}=0,1726$ at 30 minutes; EN2 vs FGF2 $\mathrm{p}=0,0463$ at 5 minutes and $\mathrm{p}=0,0011$ at 30minutes by one-way ANOVA followed by Tukey's post-tests) (C) PHPLC-GFP distribution in EN2* cell clone before (ctrl) and after induction of EN2* secretion with biotin (Biotin) for $30 \mathrm{~min}$ (D) Kinetics of PHPLC delocalization following induction of protein secretion in EN2* or FGF2* cell clone $(n>18$; for EN2: t10 Vs t0 p=0,0517 and t20 Vs t0 p=0,0017 and t30 Vs t0 p=0,0090; for FGF2: t10 Vs t0 p=0,0036 and t20 Vs t0 $p=0,0434$ and $\mathrm{t} 30 \mathrm{Vs}$ t $0 \mathrm{p}=0,0018$ by one-way ANOVA followed by Tukey's post-tests). Bar: $20 \mu \mathrm{m}$ 

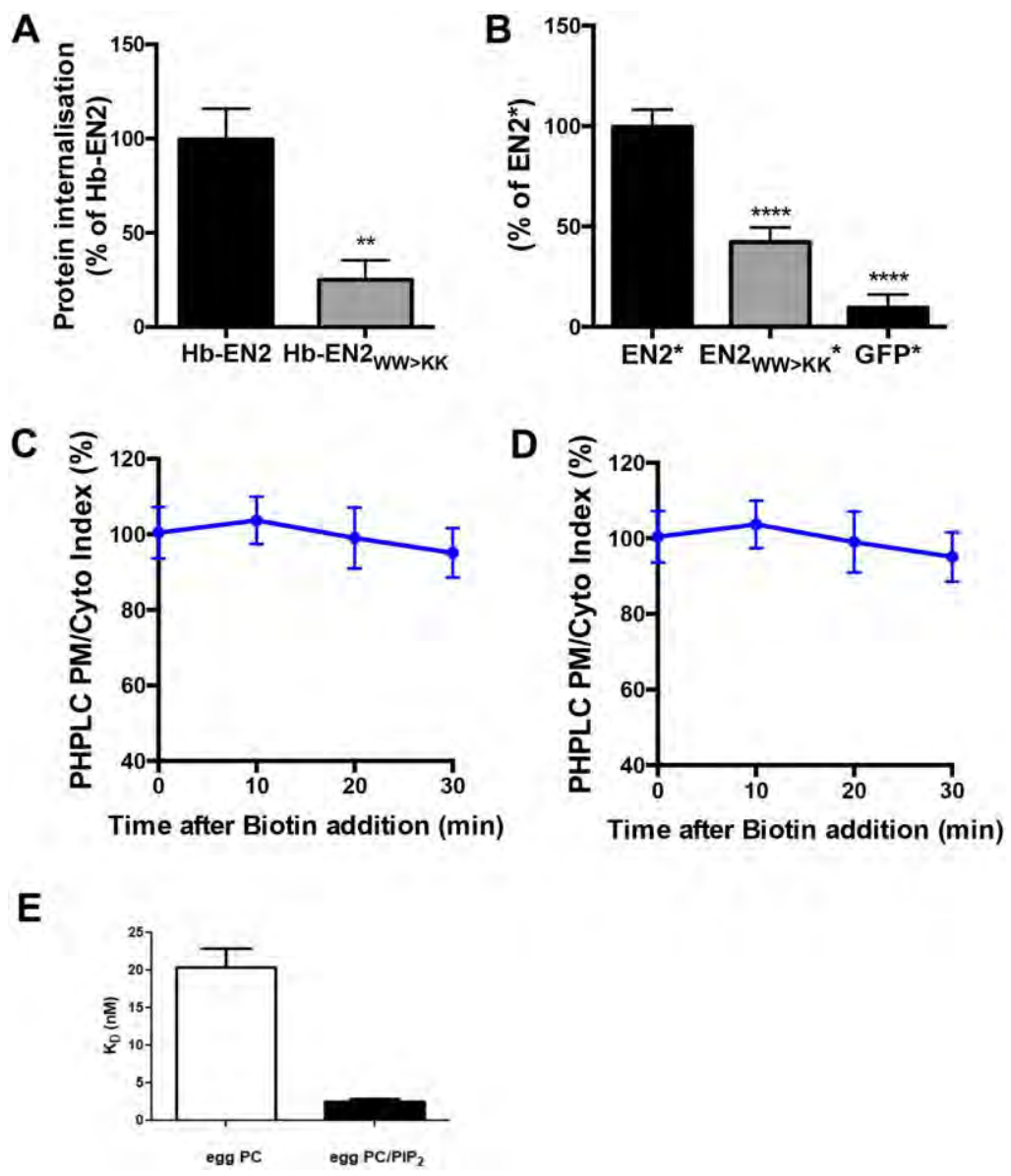

Figure 7: The impaired ability to transfer of $\mathrm{EN} \mathbf{2}_{\mathrm{WW}>\mathrm{KK}}$ mutant correlates with its reduced affinity for $\mathrm{PIP}_{2}$

Analysis of EN2 ${ }_{\mathrm{WW}>\mathrm{KK}}$ mutant in (A) internalization $(\mathrm{n}=5 ; \mathrm{p}=0,0053$ by Student's t-test) and (B) secretion assays ( $\mathrm{n}=14 ; \mathrm{p}<0,0001$ by one-way ANOVA followed by Tukey's post-tests). Quantification of GFP-PHPLC delocalization following (C) extracellular addition of $2 \mu \mathrm{M} \mathrm{EN} 2_{\mathrm{WW}>\mathrm{KK}}(\mathrm{n}=15$; t10 Vs t0 p=0,9923 and t30 Vs t0 p=0,9729 by one-way ANOVA followed by Tukey's post-tests) and (D) upon stimulation of EN2 ${ }_{\mathrm{WW}>\mathrm{KK}}{ }^{*}$ secretion by biotin addition $(\mathrm{n}=21 ; \mathrm{t} 10 \mathrm{Vs} \mathrm{t} 0 \mathrm{p}>0,7834$ and $\mathrm{t} 30 \mathrm{Vs}$ t0 $\mathrm{p}=0,7834$ by one-way ANOVA followed by Tukey's post-tests) (E) Interaction and affinity of EN2 ${ }_{\mathrm{WW}>\mathrm{KK}}$ with artificial planar lipid bilayers composed of egg PC and egg PC/PIP2 (9/1 mol/mol) measured by PWR ( $n=3 ; p=0,0003$ by Student's t-test). 
Table S1: Description of proteins analyzed in trafficking assays

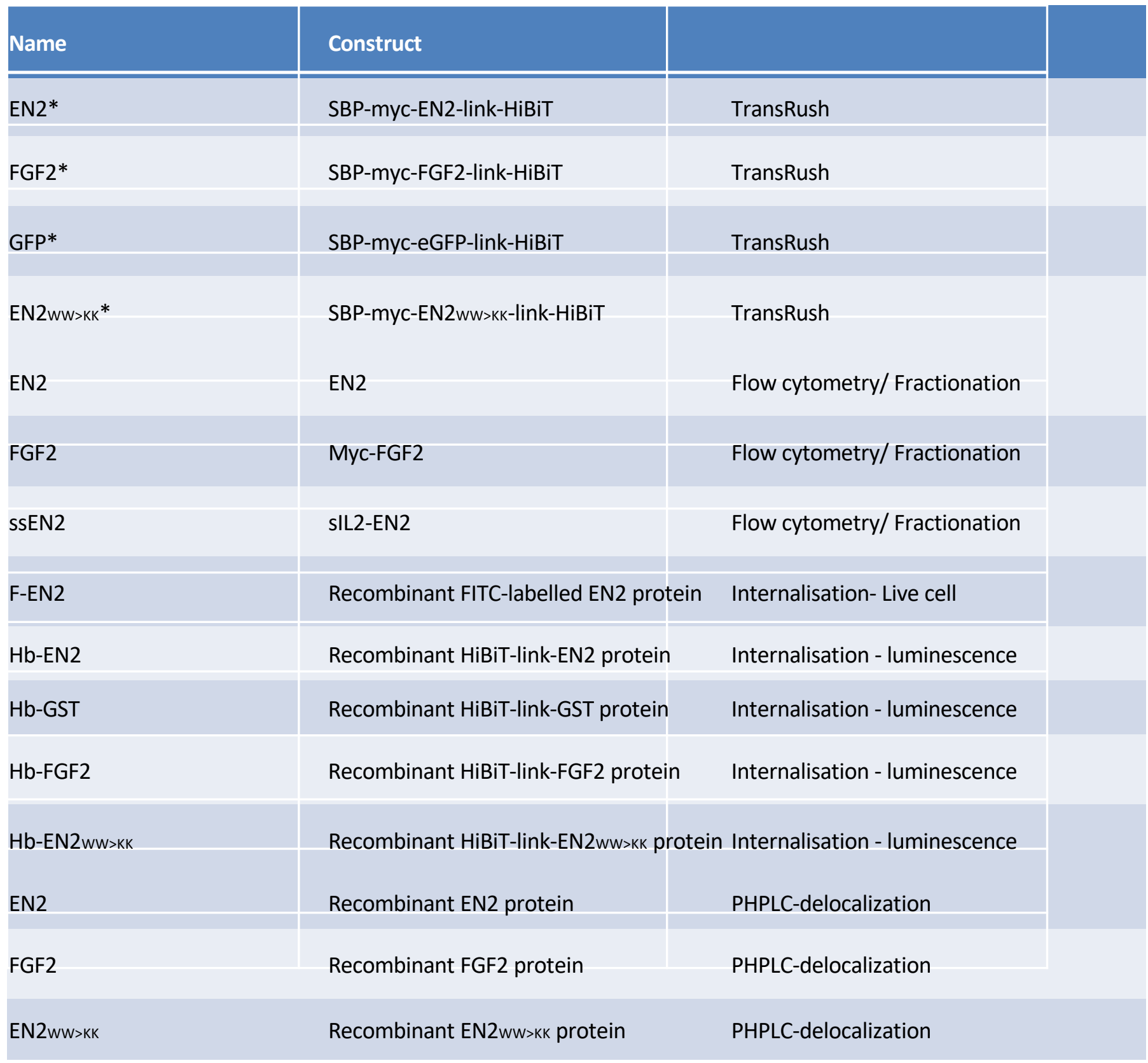

$\begin{array}{llll}\text { EN2 } & : & \text { Chick Engrailed-2 } \\ \text { EN2 }_{\text {ww>KK }} & : & \text { Chick Engrailed-2 (W169K, W172K) } \\ \text { FGF2 } & : & \text { Human FGF2 18KDa isoform } \\ & & \\ \text { HiBiT } & : & \text { small fragment of the split NanoBit (Promega }{ }^{\mathrm{TM}} \text { ) (V S G W R L F K K I S) } \\ \text { Link } & : & \text { Linker (SGSSGGSSGGNSGGGS) } \\ \text { Myc } & : & \text { Myc Tag (EQKLISEEDL) } \\ \text { SBP } & : & \text { streptavidin-binding Peptide (Peptide C4, Wilson et al. 2001) }\end{array}$


Table S2: DNA constructs and corresponding expressed proteins

\begin{tabular}{|c|c|c|c|}
\hline Plasmid name & Skeleton & Promoter & Expressed protein \\
\hline PCDNA2LCK-eCFPFRB & pcDNA5 & $\mathrm{CMV} /$ tetO & LCK-eCFP-FRB \\
\hline PCDNA2SRC-ACEPFRB & pcDNA5 & $\mathrm{CMV} /$ tetO & SRC-eCFP-FRB \\
\hline PEDAA7LCK-St-Cherfy & pcDNA5 & CMV/tetO & LCK-Strep-mCherry \\
\hline PeBNAZCher-FKBP-Bom & pcDNA5 & $\mathrm{CMV} /$ tetO & mCherry-FKBP-5Dom \\
\hline peGPPPHPLC(1) & peGFP & CMV & eGFP-PHPLCD1 \\
\hline pL2ICherry0CRL-sGbI-TIVII-st & pT2iCBi & $\mathrm{sCMV}<>\mathrm{CMVmin}$ & mCherryOCRL<>SiL-LgBiT-TM1-Strep \\
\hline pL2iCherryPI4P5K-sGbi-TM1-St & pT2iCBi & $\mathrm{sCMV}<>\mathrm{CMVmin}$ & mCherryPI4P5K<>SiL-LgBiT-TM1-Strep \\
\hline pT2iCherry-sGbi-TM1-St & pT2iCBi & $\mathrm{sCMV}<>\mathrm{CMV} \min$ & mCherry<>SiL-LgBiT-TM1-Strep \\
\hline pKhCTagScEN2 & pSCodon1.2 & $\mathrm{T7}$ & His6-CheTag-Sci-EN2 \\
\hline pKhCTagScFGF2 & pSCodon1.2 & $\mathrm{T7}$ & His6-CheTag-Sci-FGF2 \\
\hline pKhCTagScEN2 ${ }_{w w>K K}$ & pSCodon 1.2 & T7 & His6-CheTag-Sci- EN2(W169,172K) \\
\hline pKhCTagScHbEN2 & pSCodon 1.2 & $\mathrm{~T} 7$ & His6-CheTag-Sci-HiBiT-link-EN2 \\
\hline pKhCTagScHhEGE2 & pSCodon 1.2 & $\mathrm{T7}$ & His6-CheTag-Sci-HiBiT-link-FGF2 \\
\hline pKhETagSeHbEN2 & pSCodon 1.2 & $\mathrm{~T} 7$ & His6-CheTag-Sci-HiBiT-link-EN2(W169,172K) \\
\hline plkhefagscthbGST & pSCodon 1.2 & $\mathrm{T7}$ & His6-CheTag-Sci-HiBiT-link-GST \\
\hline pKhCTagScLgBiT & pSCodon 1.2 & $\mathrm{T7}$ & His6-CheTag-Sci-LgBiT \\
\hline
\end{tabular}

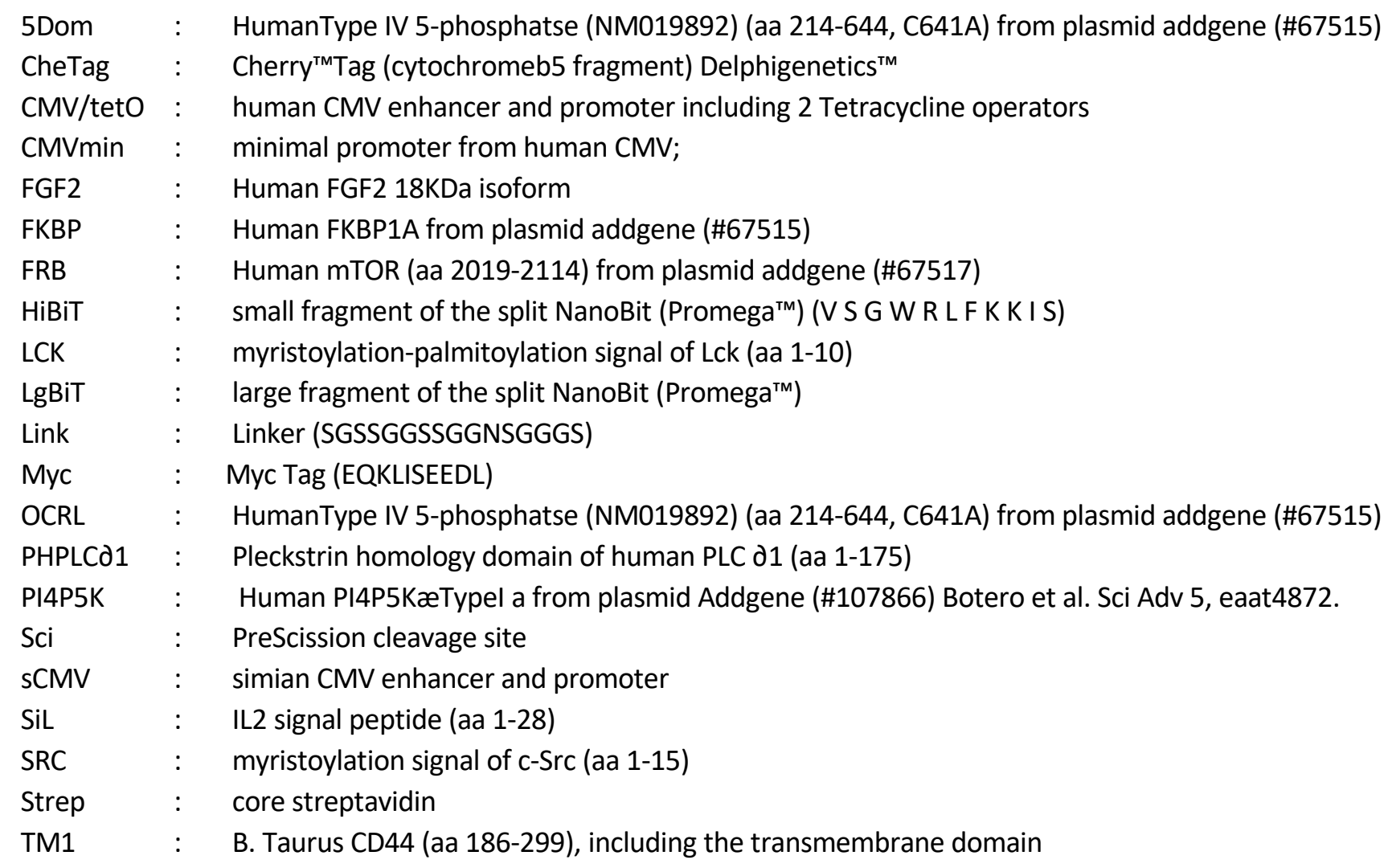


Table S3: Plasmid used for the generation of HeLa Cell lines

\begin{tabular}{|c|c|c|c|}
\hline Plasmid name & Skeletoh & Promoter & $\begin{array}{l}\text { Expressed Protein } \\
\text { (cf ahbreviation) }\end{array}$ \\
\hline pCDNA7EN2 & pcDNA5 & $\mathrm{CMV} /$ tetO & EN2 \\
\hline PaDNAZsaENR & pcDNA5 & $\mathrm{CMV} /$ tetO & SiL-EN2 \\
\hline PCDAA7MAYEEGE2 & pcDNA5 & $\mathrm{CMV} /$ tetO & Myc-FGF2 \\
\hline PEBNA7ENZ* & pcDNA5 & $\mathrm{CMV} /$ tetO & SBP-myc-EN2-link-HiBiT \\
\hline PCONAFFGF2* & pcDNA5 & $\mathrm{CMV} /$ tetO & SBP-myc-FGF2-link-HiBiT \\
\hline PCDNATGFP* & pcDNA5 & $\mathrm{CMV} /$ tetO & SBP-myc-GFP-link-HiBiT \\
\hline pcDNA7EN2 ${ }_{w w>k \kappa}{ }^{*}$ & pcDNA5 & CMV/tetO & SBP-myc-EN2(W169,172K)-link-HiBiT \\
\hline PcDNA7LgBiT & pcDNA5 & $\mathrm{CMV} /$ tetO & LgBiT \\
\hline
\end{tabular}

$\mathrm{CMV} /$ tetO $\quad$ human $\mathrm{CMV}$ enhancer and promoter including 2 Tetracycline operators

$\begin{array}{lll}\text { EN2 } & : & \text { Chick Engrailed-2 } \\ \text { EN2 }_{\text {ww>KK }} & : & \text { Chick Engrailed-2 (W169K, W172K) } \\ \text { FGF2 } & : & \text { Human FGF2 18KDa isoform } \\ \text { HiBiT } & : & \text { small fragment of the split NanoBit } \text { (Promega }^{\mathrm{TM}} \text { ) } \\ \text { LgBiT } & : & \text { large fragment of the split NanoBit } \text { (Promega }^{\mathrm{TM}} \text { ) } \\ \text { Link } & : & \text { Linker (SGSSGGSSGGNSGGGS) } \\ \text { Myc } & : & \text { Myc Tag (EQKLISEEDL) } \\ \text { SiL } & : & \text { IL2 signal peptide (aa 1-28) }\end{array}$


Fig. S1 : Behaviour of FGF2 in secretion and PIP2 Interaction assays

A

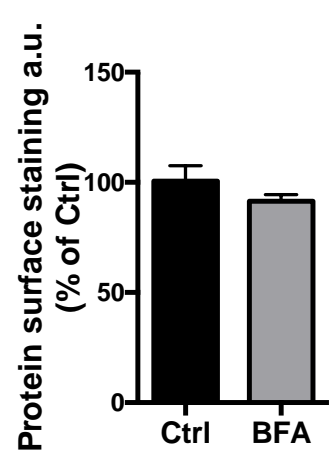

C

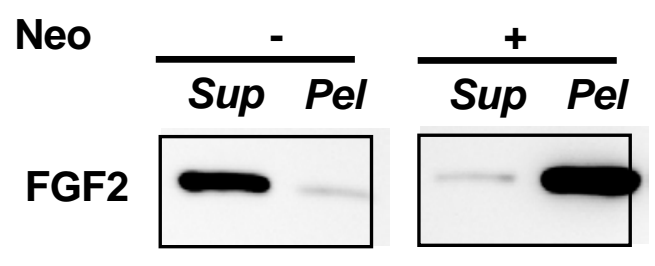

B

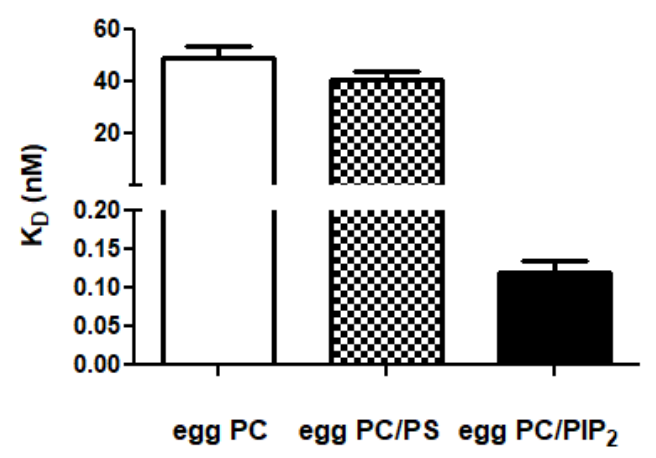

egg PC egg PC/PS egg PC/PIP 2

Fig S1: FGF secretion and PIP2/FGF interaction

(A) Insensitivity of FGF2 secretion to Brefeldin A treatment as in Fig.1A. (B) Binding affinity of FGF for lipid membranes composed of egg PC, egg PC/DOPS (3/1 mol/mol) and egg PC/PIP2 (9/1 mol/mol) as in FIG. $1 \mathrm{E}$. 
Fig S2 : Validation of RUSH tool for FGF2 for permeabilized and unpermeabilized cells

A

FGF2*

LckStrepCherry
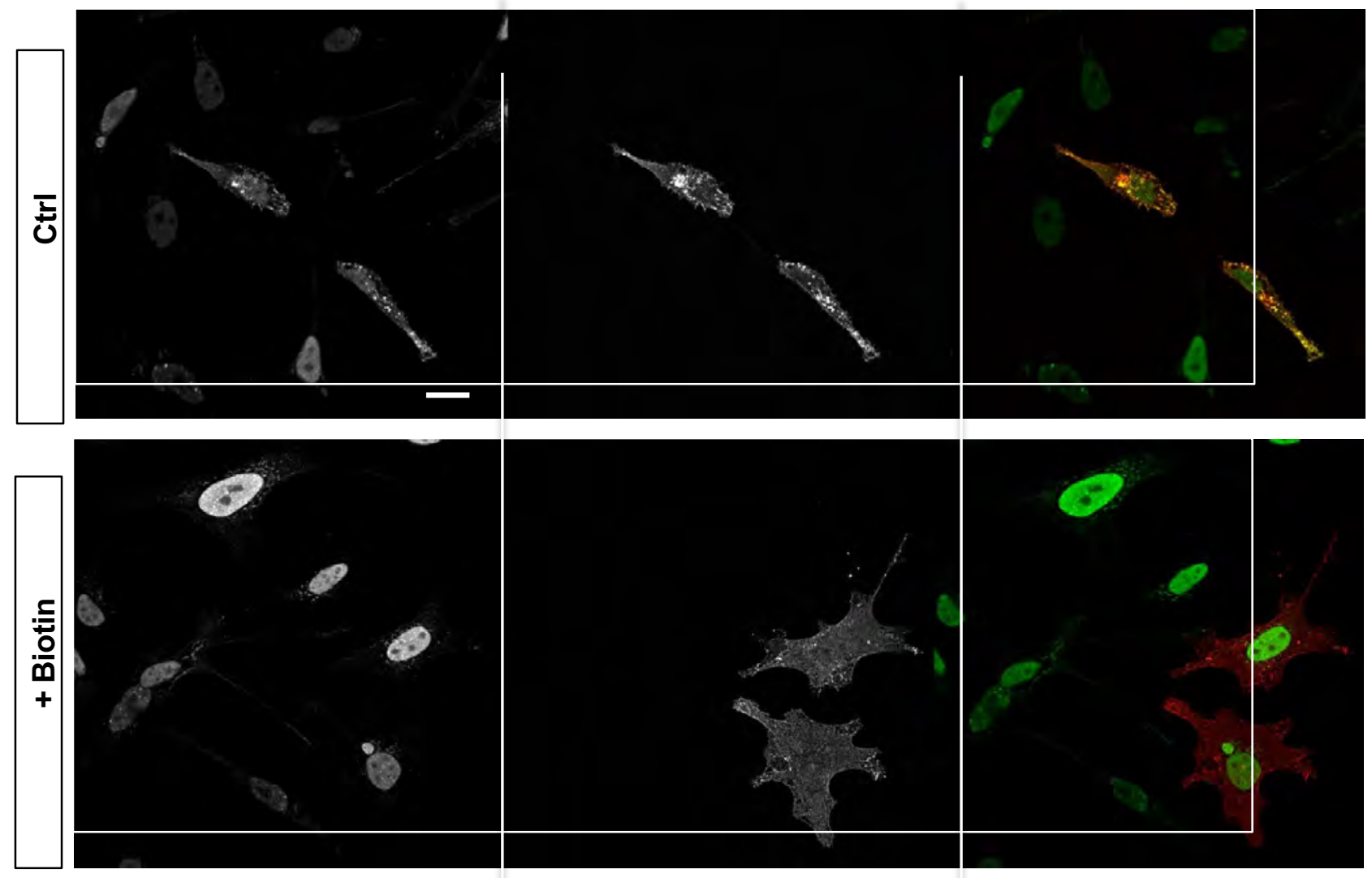

B
FGF2*
LckStrepCherry

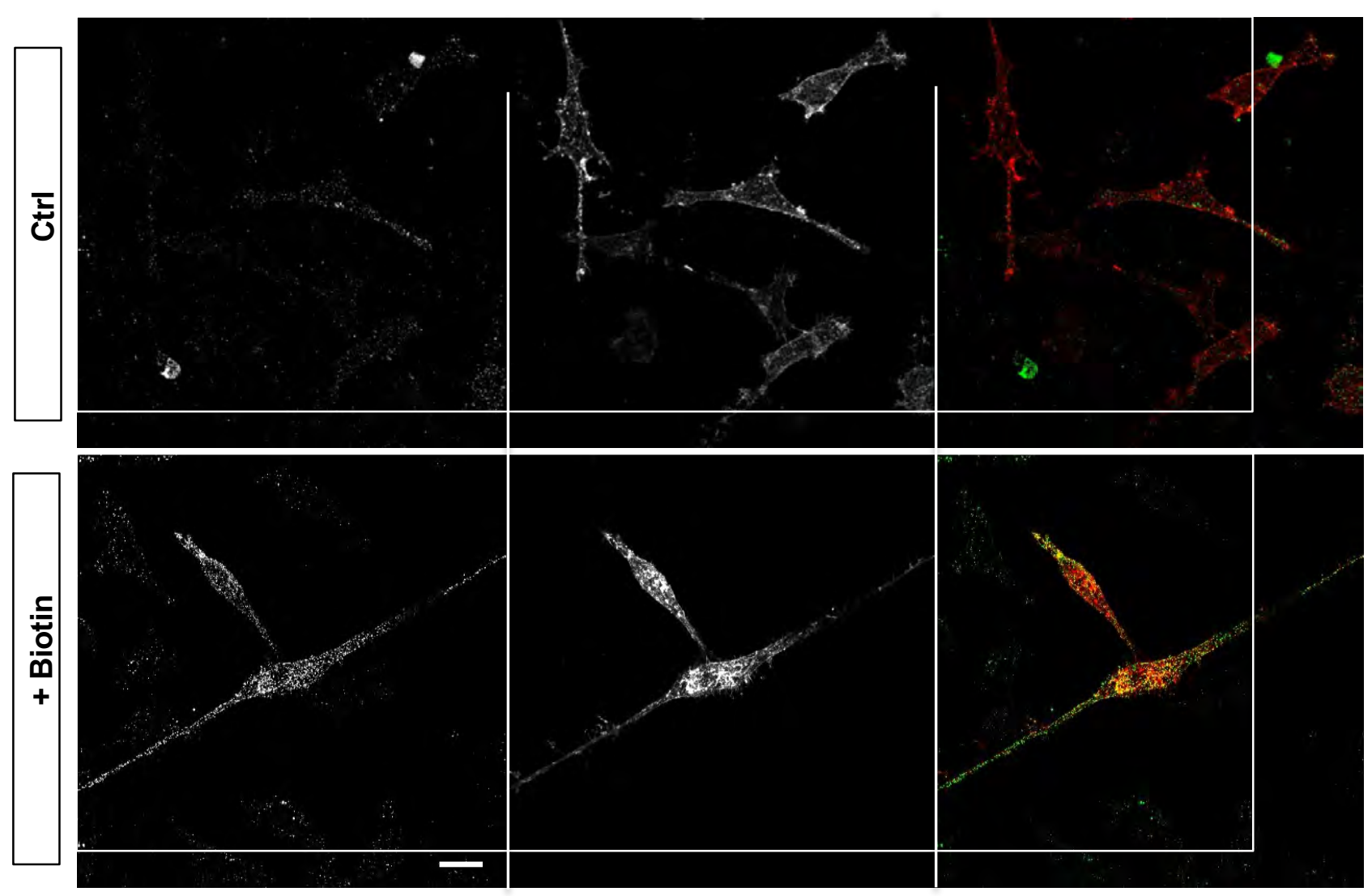


Fig S2 : Validation of Rush assay for FGF2 in permeabilized and unpermeabilized cells

Stable HeLa cell lines expressing FGF2* were transfected with a LCKStrepCherry construct and treated or not with Biotin (60 min, $100 \mu \mathrm{M})$. A) Intracellular or B) extracellular FGF2* was detected by immunofluorescence using anti-myc antibody in permeabilised or unpermeabilized conditions respectively together with Cherry staining (red) . 
Fig S3 : F-EN2 staining in cell culture

A

$561 \mathrm{~nm}:$ TB

$488 \mathrm{~nm}$ : F-EN2

$642 \mathrm{~nm}:$ WGA / TB
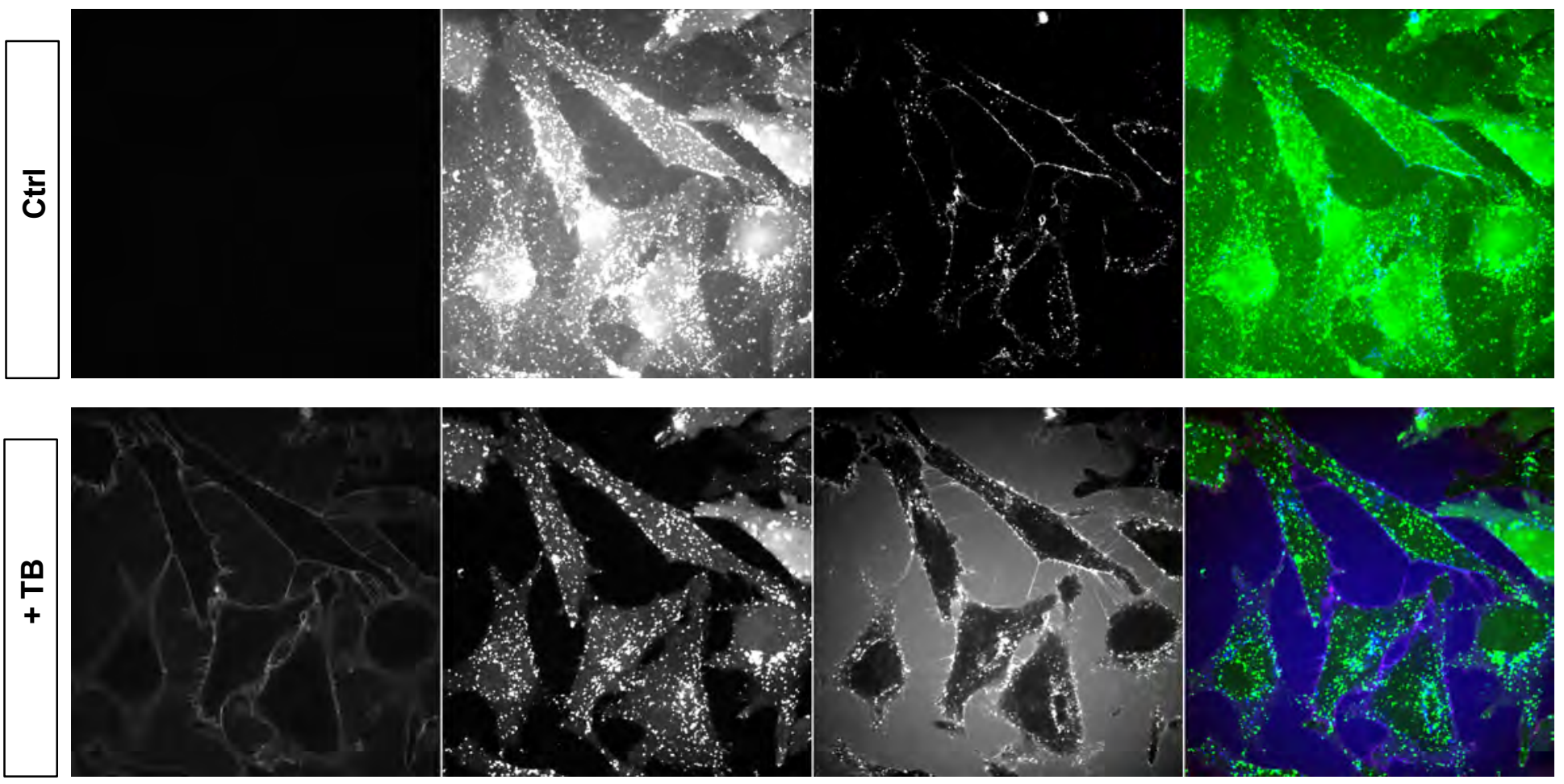

B

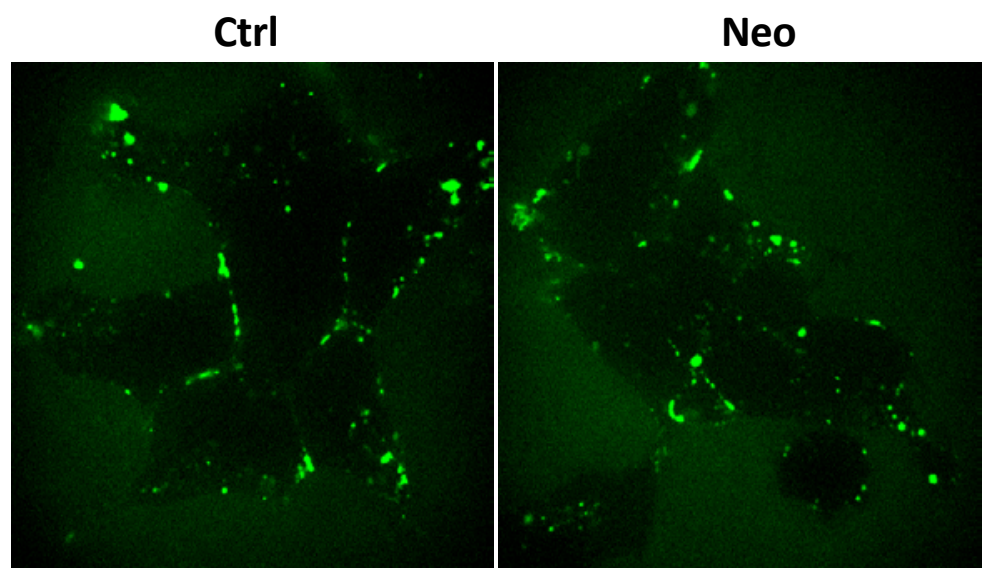

Fig S3 : Neomycin treatment does not affect EN2 extracellular localisation

(A) Live cell F-EN2 $(2 \mu \mathrm{M})$ staining from a single field acquired before (Ctrl) and after (+TB) trypan blue addition. Alexa633-WGA was added before TB to vizualize cell contours. Images were processed identically.

(B) Cells pretreated with neomycin (neo) or not (ctrl) and incubated with F-EN2. Extracellular F-EN2 was visualised (before trypan blue addition). 
Fig S4: Role of Cholesterol in EN2 trafficking

A

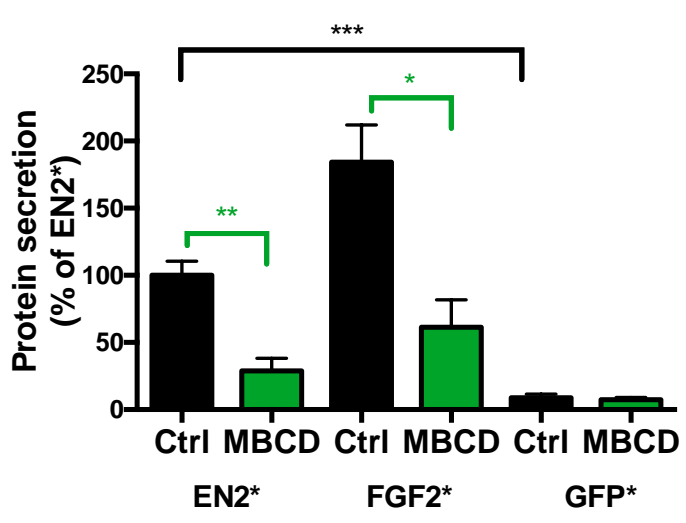

C
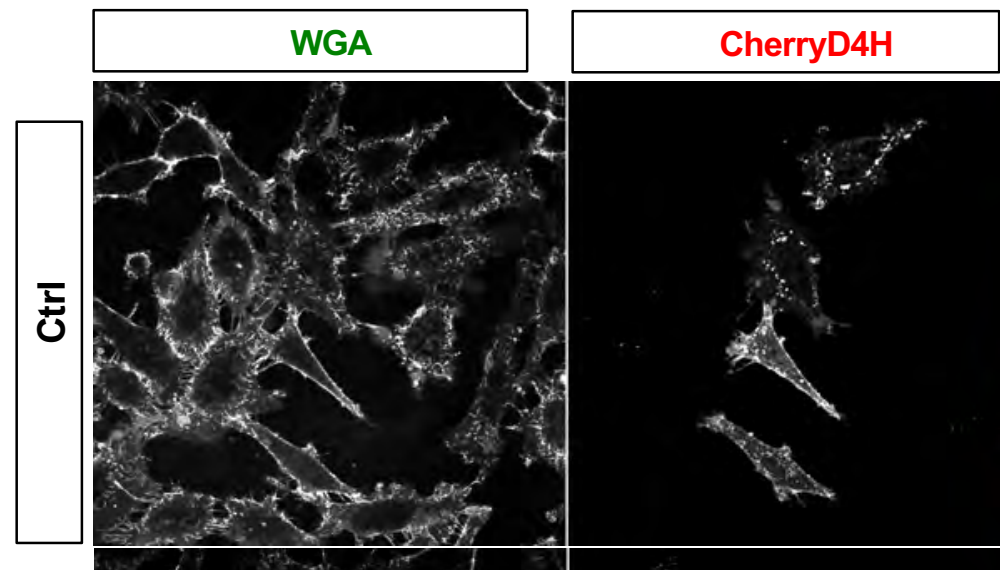

B

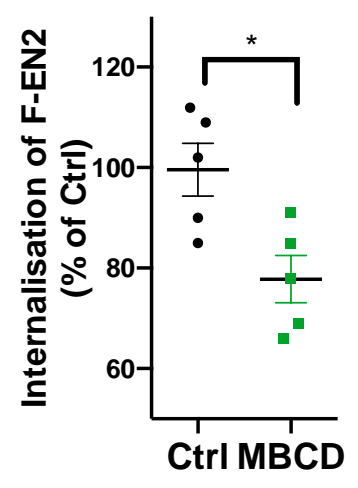

Fig S4 : MCB treatment impairs EN2* and FGF2* secretion and EN2 internalization

(A) Quantification of biotin induced EN2*, FGF2* and GFP* protein secretion in cells pre-treated or not with $10 \mathrm{mM}$ MBCD for 30 minutes. (B) Quantification of Intracellular staining in live cells following 1 hour incubation with F-EN2 $(2 \mu \mathrm{M})$ in the presence or not of $10 \mathrm{mM}$ cyclodextrin (MBCD). (C) Delocalisation of the cholesterol-binding sensor Cherry D4H following overnight treatment with U18666A compared to Ctrl conditions. 
Fig S5 : Accumulation of PIP2 and LCK anchor reporter in rafts
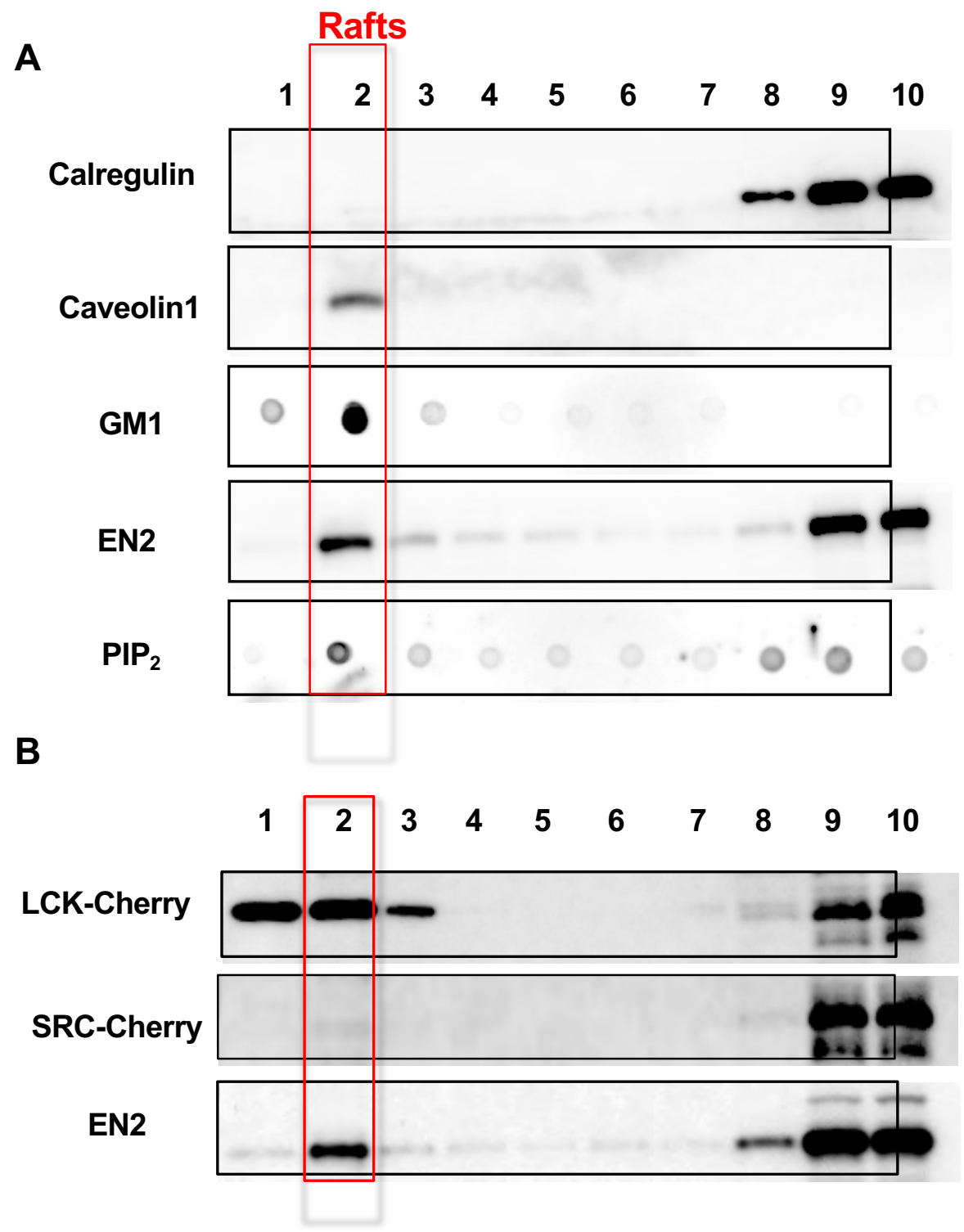

Fig S5: Role of raft associated PIP2

(A) The raft (cholesterol-enriched) membrane fraction purified from EN2 cell line, characterized by the presence of Caveolin1 and GM1 ganglioside (Cholera toxin staining) and the absence of ER marker Calregulin, is enriched both in PIP 2 (KT10 antibody staining) and EN2.

(B) The LCK anchor, but not the SRC one, drives a mCherry reported toward raft fractions 
Fig S6 : Differential sensitivity of PHPLC and LCK anchor delocalisation to EN2 addition

A

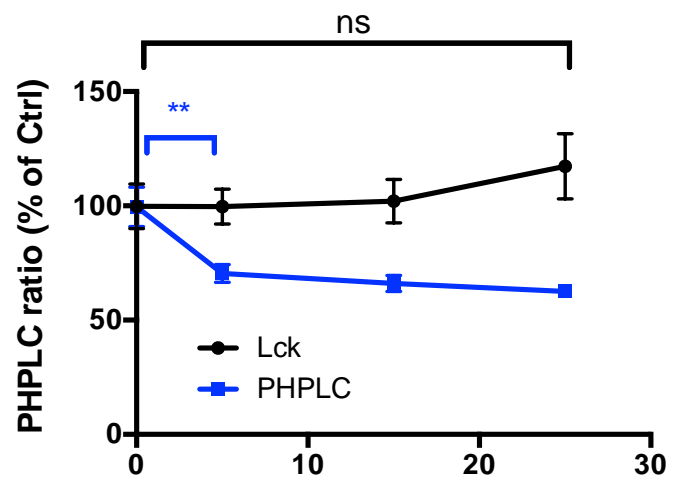

Time after Engrailed2 addition (Minutes)

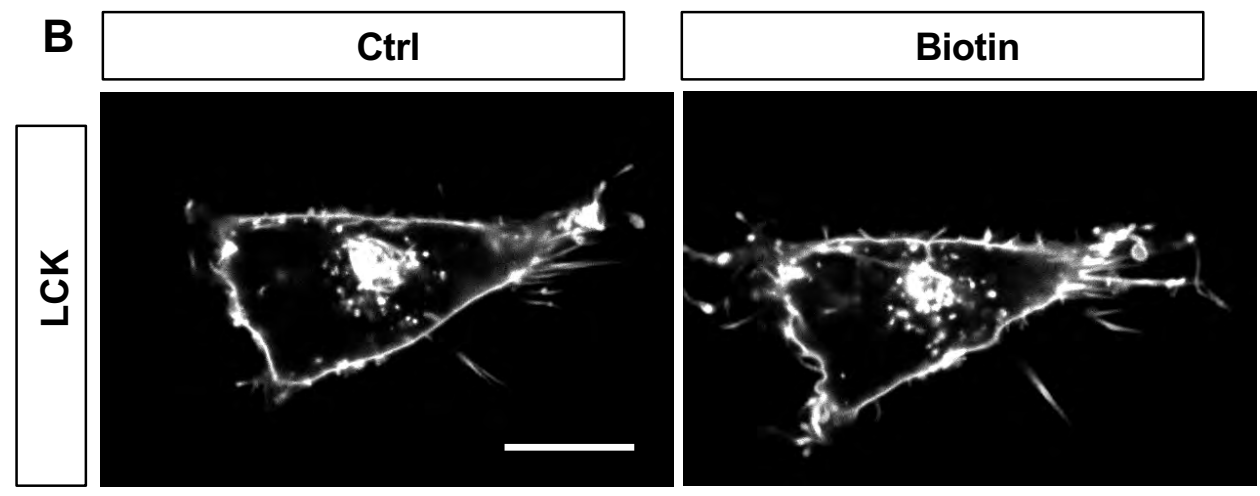

Fig S6 PHPLC/LCK delocalisation

Quantification of PHPLC or LCK-Cherry delocalisation (PM/Cytosol ratio) from the plasma membrane following extracellular addition of $2 \mu \mathrm{M}$ EN2. 
Fig S7: Protein Interaction with PIP2- coated beads

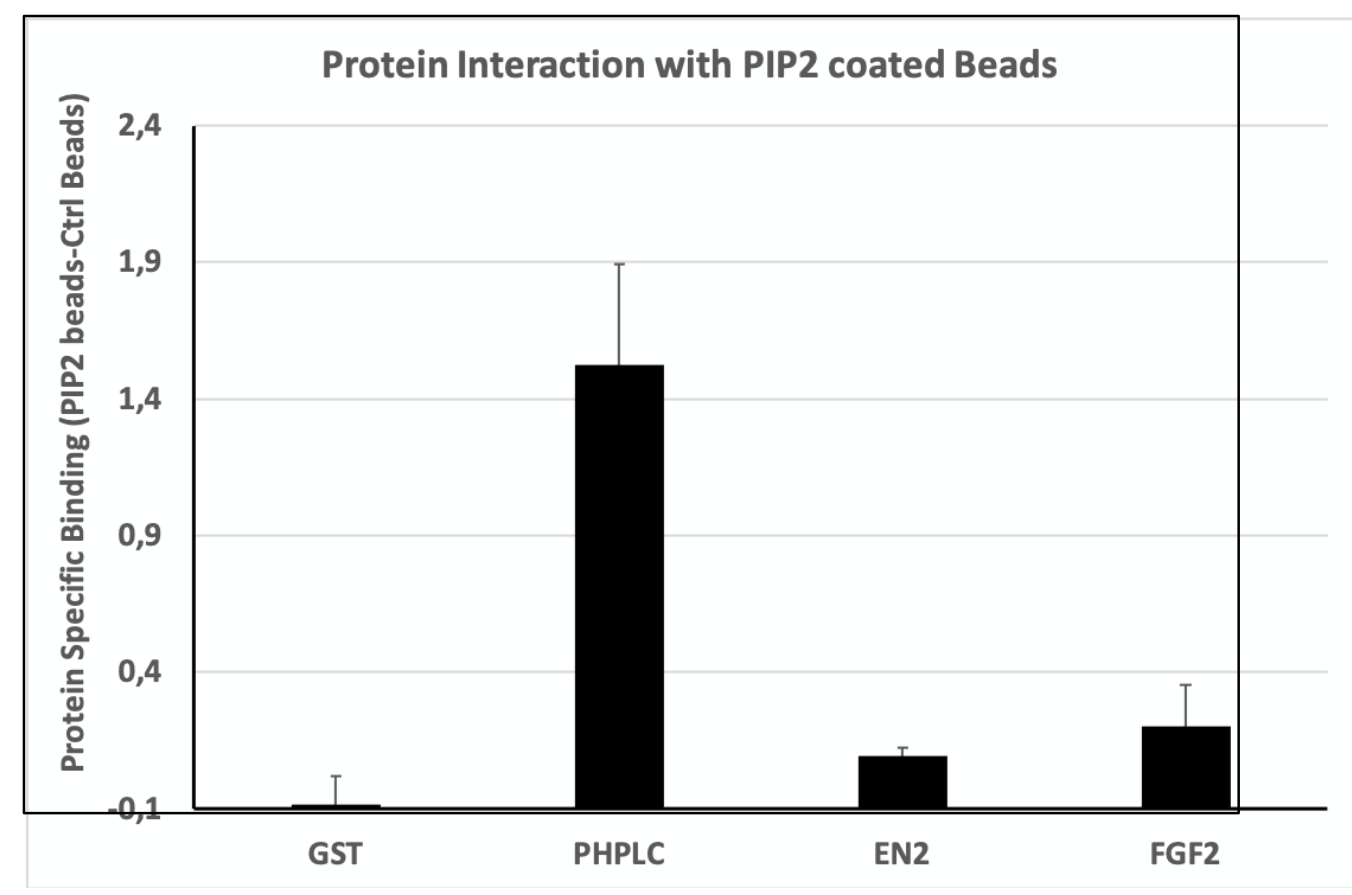

Fig S7 : Protein Interaction with PIP2- coated beads

$5 \mu \mathrm{g}$ of the indicated recombinant proteins were incubated with PIP2 or Ctrl beads and processed according to manufacturer instructions. The specific interaction (PIP2 beads - Ctrl Beads) was measured for each protein 